\title{
go 80 INDUSTRIAL ECONOMICS
}

IFN Working Paper No. 1131, 2016

\section{Wealth Inequality in Sweden: What Can We Learn from Capitalized Income Tax Data?}

Jacob Lundberg and Daniel Waldenström 


\title{
Wealth Inequality in Sweden: What Can We Learn from Capitalized Income Tax Data?*
}

\author{
Jacob Lundberg ${ }^{+}$and Daniel Waldenström ${ }^{\ddagger}$
}

\begin{abstract}
This paper presents new estimates of wealth inequality in Sweden during 2000-2012, linking wealth register data up to 2007 and individually capitalized wealth based on income and property tax registers for the period thereafter when a repeal of the wealth tax stopped the collection of individual wealth statistics. We find that wealth inequality increased after 2007 and that more unequal bank holdings and apartment ownership appear to be important drivers. We also evaluate the performance of the capitalization method by contrasting its estimates and their dispersion with observed stocks in register data up to 2007. The goodness-of-fit varies tremendously across assets and we conclude that although capitalized wealth estimates may well approximate overall inequality levels and trends, they are highly sensitive to assumptions and the quality of the underlying data sources.
\end{abstract}

JEL Classification: D31, H2, N32

Keywords: Wealth distribution, capitalization method, investment income method, Gini coefficient, top wealth shares, Great Recession

\footnotetext{
+ Jacob Lundberg

Department of Economics

Uppsala University

P.O. Box 513

75120 Uppsala, Sweden
}

\author{
${ }^{\ddagger}$ Daniel Waldenström (corresponding author) \\ Research Institute of Industrial Economics \\ (IFN) \\ P.O. Box 55665 \\ 10215 Stockholm, Sweden \\ e-mail: daniel.waldenstrom@ifn.se
}

We have received constructive comments from Facundo Alvaredo, Tony Atkinson, Laurent Bach, Thomas Piketty, Jukka Pirtillä, Emmanuel Saez, Clara Martínez-Toledano Toledano, Gabriel Zucman and seminar participants at the 4th SEEK conference in Mannheim and the Norface workshop in Uppsala, June 2015. Financial support from the Swedish Research Council is gratefully acknowledged. 


\section{Introduction}

The question of how wealth inequality has evolved over the years after the Great Recession has received a lot of attention in the policy debate, but even so there are few attempts in the academic literature to study the issue. One major reason for this lacuna is an absence of consistent longitudinal household wealth data, largely because few countries tax wealth and therefore do not systematically collect information about household balance sheets. In a recent effort to overcome this dearth of information, Saez and Zucman (2016) estimate top wealth shares in the United States using capitalized income tax data on interest earnings, dividends and interest payments, finding that wealth inequality has increased almost as dramatically as income inequality since the 1990 s. $^{1}$

In this study, we examine how the wealth distribution in Sweden has evolved between 2000 and 2012 and to do this we also implement a similar capitalization methodology as Saez and Zucman (2016) using Swedish micro data registers over income tax returns. In 2007 a centerright party coalition came to power in Sweden after a long period of Social Democratic rule. Among its first reforms was the repeal of the wealth tax, which meant that the tax authorities had to stop collecting information about individual wealth positions. As a consequence, no one has computed the level of wealth inequality in Sweden after 2007. Besides the wealth tax repeal this government implemented other reforms that could have influenced the wealth distribution, such as removing the progressiveness of property taxation and extending tax breaks for profit distribution for small business owners, both which are likely to have increased inequality, but also cutting income taxes and lowering replacement rates in social insurance, which may have induced wealth accumulation lower down the distribution.

Our study has three main purposes. First, we wish to estimate individual wealth holdings and overall wealth inequality among Swedish adults for the years since the wealth tax repeal. These estimates are the first of their kind for Sweden during this period. ${ }^{2}$ We construct a wealth register by combining observed stocks of some assets and debts (tax assessed property, listed dividend-paying corporate shares, and student loans for higher education) and capital-

\footnotetext{
${ }^{1}$ This result goes counter to trends found in wealth surveys it is currently scrutinized by others and it is fair to say that consensus is not yet reached (see, e.g., Kopczuk, 2015; Wolff, 2015; Bricker et al., 2015).

${ }^{2}$ The previous main study of trends in Swedish wealth concentration, Roine and Waldenström (2009), ends in 2006. Statistics Sweden published two internal documents in which they have calculated capitalized asset and liabilities for some years before 2008 and the assessed the goodness of fit relative observed wealth positions (see Statistics Sweden, 2010, 2012).
} 
ized stocks of financial assets and debts using records on income tax returns. Two aspects of these data should be noted. First, as we combine observed and capitalized wealth stocks, our data differ from the stocks constructed by Saez and Zucman (2016) for the U.S. which are entirely based on capitalized estimates. Like them, however, we do scale up all assets to match their respective aggregate amounts in the national and financial accounts. Second, our series are primarily aimed at prolonging the existing wealth distribution statistics previously produced by Statistics Sweden until 2007, which implies that the partial coverage of some assets in Statistics Sweden's series is sustained in our new estimates. ${ }^{3}$

A second purpose of the study is to evaluate the goodness-of-fit of estimates constructed by the capitalization method. The basis for doing this is to compare the capitalized stocks with their observed equivalents in the register data. Sweden kept a detailed Wealth Register from 2000 to 2007, containing third-party reported assets and liabilities of all individuals in current market value. ${ }^{4}$ We make several robustness checks. One concerns the crucial assumption of the capitalization method, that yields are essentially the same for all wealth levels. We also individually contrast capitalized and register-data wealth levels and their distributional outcomes in the whole population for different asset and debt categories. Systematically testing the accuracy of the capitalization method against observed wealth stocks in individual register data appears to be specific contribution to the literature. Atkinson and Harrison (1978, chapter 7) made a similar exercise, contrasting the capitalization method (or investment income method) using estate inventories as basis for estimating wealth distributions in the U.K. data around 1970. Their main finding was that estate inventories on the whole offered a more reliable picture and were therefore to be preferred. Fagereng et al. (2016) examine the consistency of capitalized estimates of financial assets using Norwegian register data, pointing at an overall poor performance of the capitalization method in matching the Gini coefficient.

The third purpose is put the recent Swedish wealth inequality trends in international perspective. Doing so helps us distinguish between the distributional consequences of the Great Recession (which affected most developed countries) from the political shift in the Swedish politics when a new center-right alliance was elected after many years of Social Democratic reign

\footnotetext{
${ }^{3}$ The coverage of unincorporated business equity and funded pension assets is limited both in Statistics Sweden's Wealth Register and in our new estimates concerns. We argue in sections 2 and 3 that this should have limited influence on our basic results.

${ }^{4}$ The Wealth Register begins in 1999 but we have excluded this year from the analysis as it was the first year of data collection and it contains unexplainable patterns in the data.
} 
(which affected only Sweden). Recent studies on Germany (Grabka and Westermeier, 2014; Grabka, 2015) and the United States (Wolff, 2013, 2015; Saez and Zucman, 2016; Bricker et al. 2014) do not indicate any homogenous trend in recent Western wealth inequality. By contrast, understanding the inequality responses to the financial crises and political events seems to require in-depth analysis of country-specific conditions and outcomes.

Our main finding is that the Swedish wealth distribution has become more unequal since 2007, but by how much depends on time period considered and inequality measure used. Between 2007 and 2012, wealth inequality measured as the Gini coefficient for net wealth in the adult population rose by approximately one fifth, which is a notable increase for any wealth distribution over such short time period. Most (about two thirds) of this increase occurred during the turbulent years of 2008-2009, and decomposing the increase suggests that it in part due to widening gaps in the housing market, especially tied to the booming values of unequally held apartments, and in part to a more skewed distribution of bank savings. When we examine the evolution of top wealth shares, they tell roughly the same story of an increase since 2007 that for the most part took place during the financial crisis years. The top wealth shares increased less than the Gini coefficient, underlining that it is largely on the housing market - houses are a typical upper middle-class asset - that we detect the main driver of increased inequality.

Our evaluation of the capitalization method gives a mixed picture. Inequality trends produced by the capitalized, or rather our hybrid, estimates appear to be largely correlated with the trends observed in register sources, and practically every year-to-year change comes with the same sign in both cases. In other words, our main descriptive result that wealth inequality in Sweden has increased since 2007 rests on fairly stable grounds, as we see it. Turning to the levels estimated in the capitalization method, however, the performance is somewhat less robust. When we look at the purely capitalized stocks, there are sizeable deviations from the actual possessions, and the errors become larger the less homogenous and transparent are the underlying capital income or expense flows. Specifically, we project the value of stock exchange-listed corporate shares fairly well for companies that pay dividends but less so for those who do not. Bank deposits capitalized from average interest payments fit the actual data surprisingly poorly, reflecting primarily a significant amount of non-interest paying accounts (checking accounts) and that interest rates tend to vary across a number of dimensions (banks, individuals, account type, deposit size etc.). Measures of inequality for our estimated net 
wealth are up to fifteen percent above those of the Wealth Register, deviations being smallest for the Gini coefficient and largest for the top wealth shares. However, in the last year for which we have overlapping data, 2007, we have the best goodness-of-fit and deviations are only one or two percent for all measures used.

The remainder of the paper is structured as follows. Section 2 presents the data, including the official register data on wealth available up until 2007 and from 2008 onwards the data from income tax and property tax assessments, and the empirical strategy used to capitalize individual wealth stocks. Section 3 examines the goodness-of-fit of our method by comparing the capitalized and observed stocks until 2007. Section 4 presents the main empirical results and Section 5 compares Sweden with the contemporaneous developments in Germany and the United States. Section 6, finally, concludes and discusses future extensions.

\section{Data and estimation strategy}

We estimate the Swedish wealth distribution statistics using register data in the longitudinal individual panel database LINDA, a nationally representative 3.35 percent sample (about 300,000 individuals) administered by Statistics Sweden. This database contains records collected from numerous public registers concerning taxation, social insurance, education and demographics. We confine our analysis to the adult population, meaning 20 years and above. Wealth variables are drawn from the Wealth Register, a specifically generated database at Statistics Sweden covering the period 1999-2007. The Wealth Register contains a large number of third-party reported variables of non-financial and financial assets and debts for all individuals in Sweden. After the wealth tax repeal financial institutions were no longer obliged to report individuals' assets and debts to the authorities. Since 2008 there is no official individual wealth statistics kept at Statistics Sweden. ${ }^{5}$

The Wealth Register of Statistics Sweden is by international standards an extraordinary database of personal wealth. It covers the entire population and most of its variables emanate from third-party reports and are thus not self-reported in surveys or personal tax returns. All variables are in current market value which in the case of real estate means multiplying taxassessed values by municipal sales price ratios generated by Statistics Sweden. However, the

\footnotetext{
${ }^{5}$ For a detailed description of the Swedish wealth tax regime and its historical development, see Du Rietz and Henrekson (2015).
} 
Wealth Register is not without limitations. Particularly problematic is the limited information about non-listed business equity and occupational pension wealth. These asset components are admittedly difficult to value and, in the case of pensions, not even fully marketable, but they are still part of official wealth definitions in the System of National Accounts. According to national wealth estimates (Waldenström, 2016), household-owned non-listed business equity comprised about five percent of total assets and funded pension claims comprised about ten percent of total assets. ${ }^{6}$ Although it is beyond the scope of this paper to make a close examination of their impact on the wealth distribution, the appendix presents rough calculations suggesting rather limited (and, in particular, offsetting between unlisted equity and funded pension assets) distributional effects. ${ }^{7}$ Notwithstanding these limitations in the administrative registers, we are confident that our data are still able to reflect the essential parts of the Swedish personal wealth distribution and its trends over recent years.

Wealth is estimated separately for the following categories: real estate (including both buildings and land), apartments, bank accounts, debt, listed stocks and mutual funds. For all these categories, the method can be tested and calibrated using the data provided by the Wealth Register. Overall net wealth is estimated by simply adding all assets in these categories and subtracting debts. In this way, we exclude some assets, in particular stock options, bonds and insurance-type investment vehicles. When comparing our estimated net wealth with that of the Wealth Register for the pre-2008 period, the excluded asset classes comprise 5-15 percent (depending on year) of total net wealth in the Wealth Register (see further the sensitivity analysis in Section 3).

We make some specific consistency adjustments of the data. First, asset and liability values are scaled such that their total values match the respective amounts in the national accounts and financial accounts, compiled and reported for all years in the Swedish National Wealth Database (Waldenström, 2016). Second, we sum our estimated assets and liabilities for married individuals in tax-registered households by dividing them equally across the married spouses. This adjustment is done primarily because we observe many instances of unequal

\footnotetext{
${ }^{6}$ The Wealth Register variable "other assets" consists of the total value of self-reported items on tax returns that exceed the sum of third-party reported wealth. It is generally regarded to reflect the value of unlisted companies, cars, boats etc., and the value was approximately one tenth of the sum of these assets in the Swedish National Wealth Database (Waldenström, 2016; available at www.uueconomics.se/danielw/SNWD.htm).

${ }^{7}$ We propose different distributions scenarios with respect to defined pension assets and closely held company equity. In the most unequal scenario (no pension assets and all closely held firms owned by the top wealth decile, two thirds owned by the top percentile and one third by the top 0.1 percentile), the top percentile wealth share increases by a little more than one third (from 20 percent to 27 percent). See further Appendix table A2.
} 
division within households which is not necessarily caused by actual ownership differences but rather artefacts of the tax system. Even when married spouses own equal shares of a house, their capitalized mortgage debt computed from reported interest expenditures may show different shares. The reason is that Swedish tax returns allow married spouses to freely decide how much of their interest payments to accrue to each spouse. If only one spouse has earned income, and thus paid income taxes against which loan interests can be deducted, then this household will allocate all the interest expenses to that spouse. This may change the year after if working conditions are different. Therefore, assuming equal division in house ownership and mortgage lending removes any of this arbitrariness in the tax statistics.

\subsection{Estimating the value of non-financial assets}

Roughly half of assets are non-financial, most being owner-occupied housing and holiday homes and among richer households also commercial real estate, mainly rental buildings, and agricultural property. Property tax assessments exist for all years and we can use them to estimate the market value of real estate with reasonably high accuracy. Property is assessed every six years and transaction prices from two years before the taxation year are used to compute market value for tax purposes. In principle, the taxable value of a property should be three quarters of its market value, but because all properties are not assessed annually the taxassessed value may deviate from the benchmark. We compute annual market values from taxable values by multiplying the tax values with municipal-level sales price ratios that are provided by Statistics Sweden. ${ }^{8}$ This method has also been used by Statistics Sweden when constructing the Wealth Register and is generally accepted as providing a fair picture of the market value of real estate. It can be expressed as follows:

$$
y_{i j k t}=\gamma_{j k t} z_{i j k t},
$$

where $y$ is the estimated market value of real estate for property $i$ of type $j$ (permanent dwelling, second home, agricultural land, industrial land etc.) in municipality or county $k$ in year $t$. The sales-price ratio, $\gamma$, is computed from recent reported sales. For first and second homes, these ratios are municipal-level while for all other types, such as agricultural land, the ratios are county-level. Finally, $z$ is the property's tax-assessed value.

\footnotetext{
${ }^{8}$ Note that by using actual stocks, we completely avoid all the specific adjustments for realized capital gains that Saez and Zucman (2016) need to make when using property tax assessments as basis for estimating real estate wealth.
} 
Apartments in condominium associations are tax-assessed at the condominium association level and not with the individual proprietors. The coverage of condominium assets in the Wealth Register is deemed by Statistics Sweden to be partial, and this asset class is therefore almost certainly measured with significant error. ${ }^{9}$ We use the values reported in the registers for each individual up to 2007, and for the period thereafter we assume that no apartments have been bought or sold. Individuals' wealth in apartments is simply extrapolated using county-level apartment price statistics. Needless to say, this no-transaction assumption is very strong, but it is the best we can presently do with the information at hand. Our approach results in an underestimation of wealth for those who bought an apartment after 2007 and an overestimation for those who sold after 2007. In the future it may be possible to improve estimates of wealth in apartments by using the same method as in the Wealth Register, i.e. assuming that any person who officially is living at an address is the owner (or co-owner) of that apartment, unless it is rented. Values of apartments are estimated from the balance sheets of housing associations. Error sources include people living in apartments they do not own because they are co-habiting, for example - or people owning apartments but not officially living there. Some error sources are eliminated by the new apartment register which is available from 2012. The apartment register enables the researcher to know who lives in which apartment, and not just who lives in each apartment block.

\subsection{Estimating the value of financial assets}

Financial assets comprise the second half of household assets. Bank deposits are estimated after 2007 by using a simple capitalization method whereby taxable interest income is divided by an annual average interest rate. ${ }^{10}$ The interest rate is chosen so that total bank holdings are as in the Financial Accounts. We calculate bank deposits as follows:

$$
\hat{b}_{i t}=\frac{q_{i t}}{\hat{r}_{t}}
$$

\footnotetext{
${ }^{9}$ See Statistics Sweden (2007). Furthermore, condominiums are in the official statistics defined as owner shares and thus included alongside corporate shares in the Financial Accounts (as "FA5190 Andra ägarandelar").

${ }^{10}$ We have attempted to improve on the simple capitalization method by using the rich demographic characteristics that are at our disposal (such as age, gender, income and place of residence). However, this regression approach mostly seems to add noise and is inferior to crude capitalization. The result was the same when we attempted to predict future interest rates using a regression with individual fixed effects.
} 


$$
\hat{r}_{t}=\frac{\sum_{i} q_{i t}}{B_{t}}
$$

where $b$ is bank account holdings, $q$ is interest income received (as reported to tax authorities), $r$ is the aggregate average interest rate and $B$ is aggregate bank deposits from the Financial Accounts, for individual $i$ and year $t$. Substituting $\hat{r}$ and summing over individuals gives that $\sum_{i} \hat{b}_{i t}=B_{t}$.

Corporate shares in exchange-listed companies and mutual funds are observed up until 2007, and thereafter estimated using information about dividends paid. Specifically, for dividendpaying listed shares we employ the fact that dividends are still reported by brokers to the tax authorities for the purposes of capital income taxation. This information includes the total dividend payout as well as ISIN (International Securities Identification Number) for each security. Additionally, we have received information about yearly dividends and share prices for each exchange-listed firm from the financial information company SIX. All of this information allows us to compute the number of dividend-paying shares for each individual and year. This multiplied by the market price gives us the total value of these shares. The most obvious limitation here is that not all companies pay out dividends, so these will be missed entirely (when $D=0$ in the notation used below). For such shares we assume that the individual has retained the shares, i.e. not sold any shares or reinvested any dividends since 2007. If an individual owned shares in a company in 2007 which in some later year did not pay dividends, the value of shares is assumed to be the number of shares owned in 2007 multiplied by the end-of-year closing price in the year concerned. For every year after 2007, the value of shares is thus computed as follows:

$$
\widehat{V}_{i}=\sum_{j} \frac{D_{i j}}{d_{j}} P_{j} 1\left[D_{i j}>0\right]+P_{j} n_{i j, 2007} 1\left[D_{i j}=0\right],
$$

where $V_{i}$ is the total value of shares for individual $i, D_{i j}$ is total dividends received by individual $i$ from security $j$ (from tax data), $d_{j}$ is the dividend amount per unit of security $j, P_{j}$ is the end-of-year market value of security $j$ and $n_{i j, 2007}$ is the number of shares held in 2007.

For individuals holding the same company shares over an entire year, this approach allows us 
to estimate the market value of this ownership almost exactly. A complication is that a person may receive dividends from two or more firms with the same money, as it were, if the exdividend dates differ. Hence there would be double-counting. However this should not be a major problem as most Swedish companies have their ex-dividend dates at approximately the same time in late spring. This said, this approach is associated with a measurement error that can be expected to grow over time. We have considered experimenting with constructing models using observed dividend income and their relation to non-dividend paying shares, or alternatively observed realized capital gains from the selling of financial assets, but concluded that it is not clear that they would produce less uncertain estimates.

The value of Sweden-registered mutual funds is estimated in the same way as corporate shares. Since most of them generate dividend income, their ISINs are reported to the tax authority. Using dividend and fund value data from SIX, total fund holdings can be estimated with high accuracy. However, mutual funds registered in other countries (typically Luxembourg) do not normally pay dividends for tax reasons. Here we use the same method as for shares and assume that the individual has made no sales or purchases since 2007.

\subsection{Estimating the value of liabilities}

There are two main categories of household debt: Mortgage debt and student debt. The latter consists of public loans from the student loan authority (CSN) to adults enrolled in educational programs. They represent about one tenth of all household debts (Waldenström, 2016). We observe these student loans in the LINDA register. Mortgage (and other kinds of bank) debt is estimated with a simple capitalization approach similar to the one used for bank accounts. Interest expenses are tax-deductible and therefore available in the LINDA register. For each year, interest is divided by an interest rate assumed to be the same for all individuals. The interest rate is chosen so that total debt equals the amount stated in the Financial Accounts. Non-student debt is estimated as follows:

$$
\begin{gathered}
\hat{d}_{i t}=\frac{p_{i t}}{\hat{r}_{t}}, \\
\hat{r}_{t}=\frac{\sum_{i} p_{i t}}{D_{t}},
\end{gathered}
$$


where $d$ is debt, $p$ is loan interest paid, $r$ is the aggregate average interest rate and $D$ is aggregate debt from the financial accounts. Substituting $\hat{r}$ and summing over individuals reveals that $\sum_{i} \hat{d}_{i t}=D_{t}$.

\section{Evaluating the capitalization method}

This section presents an evaluation of the capitalization method and of our estimated wealth stocks, a hybrid of observed and capitalized stocks. The method of calculating wealth through capitalizing tax return-based asset yields has received renewed attention after Saez and Zucman (2016) used it to estimate the U.S. wealth distribution since the beginning of the twentieth century. The method as such is not new; in fact, it is one of the oldest statistical approaches to constructing wealth estimates, both at aggregate and individual levels. ${ }^{11}$ However, there are few previous studies that investigate how well the method performs when it comes to generating accurate estimates, in particular concerning distributional outcomes. One exception is Atkinson and Harrison (1978, chapter 7), who thoroughly discuss the pros and cons of the capitalization method, or as they call it, the investment income method, and also compare its estimates with those generated by the estate multiplier method. ${ }^{12}$ They conclude that the capitalization method is relatively less consistent and more sensitive to assumptions made, but it should be noted that they do not use individual-level data in their comparative analysis but instead rely on aggregate evidence. ${ }^{13}$

Our rich register dataset, and especially the fact that we observe actual stocks (e.g., debt, bank accounts) and capital income flows (e.g., interest paid and received) during the period 20002007, allows us to evaluate the capitalization method by contrasting it against register records on individually held assets and liabilities.

We run two tests. First, we examine the accuracy of the basic assumption that the rate of return does not differ for different size of an assets. Second, we make individual-level compari-

\footnotetext{
${ }^{11}$ Most estimations of national wealth made a century ago relied to large extent on the capitalization method. See Atkinson and Harrison (1978) and Saez and Zucman (2016) for references and further discussion.

${ }^{12}$ The estate multiplier method is a technique that uses inverse mortality rates across age and social groups to transform the wealth of the deceased (reported in estate inventory reports) into the distribution of wealth of the living. This is has been the traditional method in the U.K. for estimating wealth distributions (see further Atkinson and Harrison, 1978, chapter 4).

${ }^{13}$ Among the most important shortcomings, the authors point out that only some assets report a cash yield and the inflexible manner by which certain assets produce a yield. Also problematic are the variation in yields across asset types and sizes of holdings (Atkinson and Harrison, 1978, pp. 199f).
} 
sons between capitalized and the observed stocks during the period 2000-2007, in terms of both levels and distributional outcomes. We do this for different classes of assets.

\subsection{Do rates of return differ across the wealth distribution?}

A crucial assumption behind the capitalization method is that interest rates and rates of return are independent of the size of the stock portfolio, bank account etc. Figure 1 offers evidence on whether this assumption holds for reported return on bank deposits and listed corporate shares and for reported interest expenses on mortgage debt in Sweden during the period 2000-2007.

Looking at bank account assets, panel a of Figure 1 plots a local regression of the average interest rate paid on the amount of bank deposits kept by each individual for three different years (Appendix graph A1 shows all years for all variables in Figure 1). Hockey stick-type patterns appear in these years, showing yields that first drop sharply at the lower end and then rise in the size of bank deposits. The pattern differs for 2006 and 2007 when implied interest rates increase almost monotonically. The reason is that these two years are based on better data as administrative routines for collecting bank holdings changed; prior to 2006 only deposits generating interests annually of 100 SEK (about 10 euros) had to be reported to tax authorities and from 2006 all bank accounts holding more than 10,000 SEK had to be reported, regardless of the amount of interest earned. This increased the number of people with positive amounts by one sixth and amounts by at least as much, primarily capturing accounts with zero interest rates (e.g., checking or salary accounts).

It is this observed positive relationship between bank deposits and interest rate that accounts for why our capitalization estimates indicate substantially higher dispersion of bank deposits than does the Wealth Register.

Panel b shows the relationship between the value of individuals' ownership of listed corporate stock and the implied dividend yield, i.e., total received dividends divided by the market value of shares. Perhaps surprisingly, we find a clear negative relationship, with dividend yields being somewhat lower for larger possessions. One possible explanation could be that individuals who do not own many shares stick to established high-dividend firms, while large investors dare venture into low-dividend growth firms whose returns are instead largely in the form of capital gains. Another explanation could be related to the fact that this analysis abstracts 
from the total stock return, which includes dividend payouts, observed on tax returns, and reinvested profits that materialize in the form of increased company values, i.e., as capital gains, and are therefore typically not observed on tax returns. Bach, Calvet and Sodini (2015) examine such a broader asset returns, and find that they are indeed higher for richer individuals. Overall, these findings indicate that the crude capitalization approach may be quite problematic, and that estimates based on taxable dividend incomes would probably underestimate the concentration of share ownership.

Lastly, panel c plots the local regressions of average interest rates on the amount of bank debt. The implied interest rate is calculated for each individual as tax-deductible interest divided by total liabilities (excluding student loans). See the appendix for a plot of all years. There is a clear negative relationship between implied interest rate and the amount of debt for all years. In 2007, those with less than 10,000 euros of debt pay an average interest rate of about 6 percent while individuals with more than 100,000 euros of debt pay around 4 percent.

As no information on type of debt is given in the Wealth Register, we can only speculate as to the cause of this finding. Perhaps those with little debt hold mostly consumer or credit card debt, while highly indebted individuals predominantly have low-interest mortgages. It is also possible that people with a lot of debt can negotiate lower interest rates with banks. If the negative relationship between debt and interest rate persists in the low interest rate environment after the financial crisis, our capitalization method will underestimate the debt levels of highly indebted people. This may explain why the capitalization method returns a lower Gini coefficient for liabilities than the Wealth Register.

[Figure 1 about here]

Figure 2 maps the variance of yields over wealth, but this time for specified fractiles in the wealth distribution contingent on individuals having positive yields (or debt payments) in each case. The overall patterns are similar as above, indicating that rates of return differ across wealth groups. There are, however, differences in how large these yield variations are, both across assets and within assets over time. Bank yields locate within a quite narrow range, between one and three percent annual interest, for all wealth holders in all years. Stock returns 
appear to decrease, possibly for the reasons discussed above. ${ }^{14}$ Bank debt interests fall in the level of wealth, with the bottom half paying 50-100 percent higher interest rates than the top 0.1 percentile. Total financial returns, finally, appear to increase over the distribution if one disregards the abnormal (stock) returns in the bottom group.

[Figure 2 about here]

Altogether, our results offer little support for the hypothesis that an individual's return on assets in general is independent of the amount owned in that asset class. Since variations differ both across assets and over time, it is difficult to offer any simple rules of thumb regarding the implications of this returns variability.

\subsection{How well do capitalized stocks capture distributional outcomes?}

We now turn to analyzing the goodness-of-fit of the estimated wealth stocks. Figure 3 shows histograms over the distribution of ratios of individual values of our estimated assets, liabilities and net wealth to their equivalent values in the Wealth Register in 2007 (Appendix Figure A2 reports the same ratios for three years: 2000, 2004 and 2007). The bar at value one on the $\mathrm{x}$-axis represents the share of adults for which the ratio is one plus/minus 10 percent deviation of the Wealth Register value, i.e., when the capitalized value is approximately equal to the stock observed in the register data. Bars below unity reflect the number of individuals for which the capitalized wealth is lower than recorded in the Wealth Register whereas bars above one accordingly reflect cases where we estimate a higher wealth than what the register shows. $^{15}$

Real estate (panel a) is well estimated: about 90 percent of individuals have values that are approximately the same as in the Wealth Register. This high degree of congruence stems from the fact that we employ the same tax-assessed property values as Statistics Sweden did when

\footnotetext{
${ }^{14}$ Average stock returns are abnormally high among the lower groups; in the excluded bottom half they range between 10 and 20 percent up until 2006 and between 30 and 40 percent thereafter. One possible reason is that we observe dividend payouts from mutual funds that are not part of the asset class considered (direct-owned corporate shares).

${ }^{15}$ For reasons of readability we have restricted the histograms to show ratios in the interval between 0 (when capitalized wealth is zero although register wealth is positive) and 2 (when capitalized wealth is twice the amount of register wealth) but there are a number of observations outside this range that naturally are worse in terms of the goodness-of-fit. These are either those where the register wealth is zero, which are dropped since the ratio is undefined, or those with a ratio above two. The relative share of these observations vary across asset classes, but appear to be the lowest for our composite wealth variables (about one tenth for net wealth) and highest for capitalized liabilities and bank deposits with up to a fifth of observations outside the $[0,2]$ interval.
} 
constructing wealth variables. Therefore it is somewhat puzzling to there remain slight deviations between our estimate and that of the Wealth Register. ${ }^{16}$ Bank deposits (panel b) exhibit a large bar at zero, suggesting that we estimate a large share (about one third) of adults as having no bank account assets even when they do hold such assets according to the Wealth Register. The main explanation for this misspecification is that these are people with deposits in interest-free bank accounts, predominantly salary and checking accounts, where no interest income is received. In equations (2) and (3), this situation corresponds to having $q=0$. Furthermore, only for less than one tenth of all adults do we estimate bank assets at the correct level. We therefore conclude that the capitalization method does a relatively poor job when estimating bank deposits.

Corporate shares (panel c) are estimated with more accuracy, with the modal bar containing two thirds of the population. The bar is located just over one, reflecting a scaling effect when adjusting to the financial accounts total (without the scaling, the high bar is exactly at one). The deviations in the figure - about one third of the cases are estimated with substantial error - reflect in part non-dividend paying corporations and in part transactions in individual portfolios between the time of the dividend receipt (usually late spring) and the end of the year when the wealth is measured. Note that after 2007, we lack information about non-dividend paying shares, which means that our estimates will be worse than the fit indicated by the figure. Furthermore, our estimates are different from the crude capitalization method using average dividend yields to scale up reported dividend incomes by individual; Figure 5 below examines how this affects the goodness-of-fit.

Gross assets in panel $d$ are the sum of financial and non-financial assets, and it shows that our estiamtes get almost two thirds of the cases just about right. Mortgage debt in panel e is estimated using the capitalization method (equations 5 and 6) and we get a relatively large dispersion of ratios to the observed debt. This relatively poor goodness-of-fit can be attributed to several different possible factors, but two of them stand out. First, individual interest rates can differ quite substantially from the grand average computed from dividing total interest payments by total bank debt. Second, when people change their debt status during the year, by either selling their house or buying a new one, this means that the end-of-year balance differs

\footnotetext{
${ }^{16}$ We have examined the possible reasons for these deviations but without finding conclusive answers. We employ the same tax-assessed stocks and municipal sales price ratios as Statistics Sweden do in their calculations. A close scrutiny of Statistics Sweden's computer code has revealed a small error that could explain some (or all) of the deviation, but this has not been verified.
} 
from what is reflected in the accumulated interest payments. Finally, net wealth ratios are shown in panel $f$ and they offer a similar, but slightly more accurate, picture compared to that shown in panel e. For the year 2007 we find that almost 40 percent of adults have about the same net wealth as shown in the Wealth Register and two thirds are within a 30 percent deviation. Absent similar investigations for other countries, we are unsure about whether this match is to be considered good, acceptable or bad. For the time being we have to accept it as it stands and that its credibility is largely in the eye of the beholder.

[Figure 3 about here]

Next, we compare Gini coefficients of our new wealth estimates compare with those of Statistics Sweden's Wealth Register. Figure 4 focuses on three asset classes (real estate, bank deposits and listed shares) and on bank debt (in next section we discuss the case of net wealth). In the case of real estate, the overall levels and trends are similar, as expected, and in the three last overlapping years, the coefficients are practically identical. Before 2005, there is the puzzling deviation that we already saw in the previous subsection, but note that its impact on the Gini is still only about a two-three percent deviation and thus hardly alarming.

For bank deposits, the distributional goodness-of-fit is not impressive. The figure depicts a very large discrepancy between the two cases: the capitalization-based Gini hovers around $0.85-0.90$ while in the Wealth Register it is around $0.75-0.85$, with a deviation of approximately five-ten percent. It should be noted, though, that the trends are fairly similar, and this also holds true for the year-to-year changes that almost always have the same sign. Having said that, the dramatic increase in 2009 may well reflect a disproportionate sensitivity of the capitalized levels as the market interest rate in this year plummeted (from 5-6 percent in 2008 to 1-2 percent in 2009) following the expansionary monetary policy push in the wake of the financial crisis.

The distribution of corporate shares listed on the stock exchange are closely matched in terms of both levels and trends over the entire period. Recall, however, that this result is largely due to the fact that we were able to observe the number of shares owned and can use this information to estimate the value of non-dividend paying shares. After 2007, this information is not available, so we assume that no transactions are made. However, as most companies pay dividends the proximity of the Gini coefficients indicates that our method works quite well. 
Bank debt excluding student loans, lastly, is distributed quite similarly in the capitalized estimates and the Wealth Register. Both series have Gini coefficients at $0.70-0.75$ and both exhibit modest downward trends except perhaps for the very last year in the overlapping period when they move in slightly different directions. ${ }^{17}$

The overall message of the distributional comparisons is in other words a bit mixed. There is a very poor goodness-of-fit in how capitalized bank deposits are distributed; its inequality trend is fairly similar across sources but the level differs considerably. In the case of real estate, listed shares and non-student liabilities, however, the picture looks better. Both levels and trends of the Gini coefficients are similar when using either capitalized or register-based wealth.

[Figure 4 about here]

Figure 5 compares distributional outcomes for corporate shares when using our estimates, the Wealth Register and a coarse capitalization approach based on taxable dividend income and aggregate dividend yield (i.e., the average return on all equity). Panel a shows the Gini in these three cases, and the main message is that the capitalization technique offers a quite bad fit, being much lower in the early period and then increasing rapidly and thus offering a quite different time trend. In panels b and c, we report the same ratios over the Wealth Register stocks as shown above, and this confirms the much worse fit of the capitalization approach for corporate shares.

[Figure 5 about here]

\section{Wealth inequality in Sweden, 2000-2012}

No one has investigated the trend in wealth inequality in Sweden over the recent years due to the dismantling of official wealth distribution statistics after the wealth tax repeal in 2007. This section therefore presents the first attempt to describe this evolution, beginning with the

\footnotetext{
${ }^{17}$ We also tried with an alternative method of estimating housing debt, based on obtained information on registered mortgages (liens) from the Swedish land registration authority (Lantmäteriet). However, the match is considerably worse than for the capitalized interest expense even though it replicates average debt levels and their trends relatively well (results available upon request).
} 
basic trends comparing wealth levels across deciles as well as some key measures of wealth inequality: top wealth shares and the Gini coefficient.

\subsection{Main trends}

Table 1 presents the distribution of our estimated net wealth among adults living in Sweden in 2012. Average wealth is 80,800 EUR but median wealth is only 10,400 EUR. The richest tenth of the population consists of people owning at least 248,000 EUR in wealth. They hold two thirds of all privately owned wealth in the country, with an average wealth of 545,000 EUR. Within this group, however, there is considerable heterogeneity. The top percentile holds 21 percent of total wealth and has an average wealth of 1.8 million EUR whereas the average wealth of the lower nine percentiles is 428 thousand EUR. In the very top, the highest 0.1 percentile, average wealth is almost 5.7 million SEK, which is about 70 times the average wealth in the whole population and the threshold for qualifying to this group, 2.8 million EUR, is 185 times the median wealth. Looking at the bottom of the distribution, the wealth share turns negative. We have reason to believe that the negative share of the bottom half is too large, reflecting insufficiencies in the capitalization methodology, but observing negative net wealth shares in the bottom is nothing unusual but in fact seen in most industrialized nations (OECD, 2015). This naturally reflects the important role of debt, which in Sweden is a combination of mortgage and educational borrowing, for wealth inequality. The share of negative net wealth is known to be much larger in Sweden than in other countries (see Cowell, 2013; Cowell and Van Kerm, 2015), and this probably reflects a combination of factors, including underlying country-differences in borrowing patterns as well as insufficient coverage of assets, e.g., that Swedes are able to borrow against their mortgage in order to purchase consumer durables which are not recorded as assets in the wealth statistics.

\section{[Table 1 about here]}

The evolution of average net wealth of each of the ten deciles in the Swedish wealth distribution during 2000-2012 is displayed in Figure 6. The figure shows both our estimated wealth and Wealth Register-wealth. Their overall trends are just about the same over the overlapping years but levels do not match perfectly. During the whole period, average wealth increased by 75 percent in real terms. Most of the increase occurred before the outbreak of the financial crisis in 2008. The figure shows that gaps are widening over the period. The top three deciles saw average wealth increase two- or threefold while the bottom three deciles experienced an 
opposite trend with net wealth dropping to even more negative levels. Comparing the trends within the top half of the distribution shows a fairly homogenous experience even though the top three deciles increased the most.

[Figure 6 about here]

The trend in overall wealth inequality, measured as the Gini coefficient of net wealth, is shown in Figure 7 (see Appendix Table A1 for all values). ${ }^{18}$ The figure presents two Gini estimates, one based on the Wealth Register for the years 2000-2007 and the other based on our capitalized wealth estimates over the full period. The main message is one of a fair degree of stability, though with two distinct periods materializing: Gini coefficient falls from 2000 until 2007 by about one tenth and then it increases by one fifth between 2007 up to 2012 . While the decrease in the first period is fairly gradual, most of the subsequent rise in dispersion takes place during 2009, the year immediately after the peak of the crisis. Another result is the Gini coefficient using capitalized wealth is higher than the Gini coefficient based on administrative register data throughout the period, although the difference falls between 2000 and 2007. ${ }^{19}$

[Figure 7 about here]

Top wealth shares offer another view of the development of wealth inequality. We saw in Table 1 that the top decile in Sweden holds approximately two thirds of all the country's private net wealth, a level that is also found today in most Western countries (Roine and Waldenström, 2015). Figure 8 presents the recent evolution of shares of total wealth owned by the top decile in Sweden, but where the decile is split up into three subgroups: the lowest nine tenths of the top decile (top 10-1\%), the lowest nine tenths of the top percentile (top 1-0.1\%) and finally the wealthiest group in the population, the top 0.1 percentile. Around 2008-2009 all series in the Figure increase, but it is only the top 10-1\% group that increases relative to the pre-2007 period; the two subgroups belonging to the top percentile merely jump back to their earlier level of the 2000s. This pattern suggests that the increased inequality documented

\footnotetext{
${ }^{18}$ Note that computing Gini coefficients for distributions containing negative values (which is often the case with net wealth) may obstruct standard normative interpretations of the Gini measure (e.g., concerning the redistribution of negative shares), but as Cowell and Van Kerm (2015) and others have pointed out the Gini coefficient is still statistically well-defined and can be used in distributional analysis.

${ }^{19}$ Kernel density estimations of both cases in year 2007 indicate that the biggest deviations are found in the lower half of the distribution (Appendix Figure A6).
} 
above in the Gini coefficient, if anything, does not seem to be primarily driven by wealth gains among the very richest. This said, seen over a longer time period, the Swedish top wealth shares of the 2000s and 2010s are still higher than they were in the 1970s, 1980s and 1990s (Roine and Waldenström, 2009). ${ }^{20}$

[Figure 8 about here]

Finally, we contrast the evolution of wealth inequality in Sweden against the contemporaneous evolution of the inequality of earnings and disposable income in the same adult population. Figure 9 shows how all series break around 2008-2009 with inequality levels being clearly higher afterwards. This simultaneity indicates how different distributional outcomes may reflect common shocks to society, e.g., a financial and economic crisis. A more direct link is offered by more unequally held bank deposits, and thus also through more unequal capital incomes, which our compositional analysis in the following section indicates matters for the increase in wealth inequality.

[Figure 9 about here]

To sum up these descriptive results, we find that the distribution of personal wealth in Sweden appears to have become more unequal since 2007 and that most of this change occurred during 2008-2009 while little has happened in the period thereafter. This said, the uncertainty in some of the estimated assets found in the previous section combined with the fact that the inequality increase occurs just around the time when we only have capitalized wealth data warrants some caution when making conclusions from these findings.

\subsection{The role of asset composition}

What mechanisms have been important for the shape and change of the wealth distribution in Sweden over the studied period? Previous studies show how differing portfolio structures across the population can matter. For example, financial assets tend to dominate the portfolios of the rich tend while middle-class people have most of their wealth in their homes (see, e.g., Guiso, Haliassos and Jappeli, 2000).

\footnotetext{
${ }^{20}$ The top decile share was 55-60 percent from the 1970s up to the 2000s, but 75 percent in 1951, 83 percent in 1935 and 92 percent in 1920 (Roine and Waldenström, 2009, table A1)
} 
Figure 10 depicts shares of asset components and liabilities in gross wealth for four quantile groups in the Swedish wealth distribution. There are notable differences between the groups: Listed shares account for 16 percent of gross assets of the top 0.1 percentile but only two percent for the bottom nine deciles. Real estate, including homes as well as rental property, agricultural land and timber tracts, and apartments comprises four fifths of assets in the bottom nine deciles and as much as two thirds in the top 0.1 percentile. While this difference is substantial, it is still much smaller than what Saez and Zucman (2016) find for the U.S.; their estimations indicate a share of housing of top 0.1 percentile portfolios of about one twentieth (5 percent) and a ten percent share in top percentile portfolios during 2000-2012. The recent survey of household finances in fifteen European countries (OECD, 2015, ch. 6) indicates that real estate shares in top percentile portfolios ranges between one third (Austria) and nine tenths (Luxembourg).

There may be several possible explanations for this large country variation. For example, differential capital taxation could matter where in Sweden particularly agricultural land and forests have been taxed relatively little as compared to other tax bases. However, this importance also reflects the fact that our Swedish capitalized wealth estimates (as well as the register data of Statistics Sweden) do not cover values of equity in closely held corporations work to suppress financial asset shares and top wealth shares significantly. ${ }^{21}$

Looking at the trends in wealth composition in Sweden shown in Figure 10, there is a much more homogenous pattern across groups. In fact, the compositional profiles hardly change and this rules out any large-scale structural changes driving household wealth distribution trends in Sweden.

[Figure 10 about here]

An alternative approach to investigate the role of asset components in wealth inequality is to compute their relative contributions to the Gini coefficient at different points in time using the methodology of Lerman and Yitzhaki (1985). Specifically, this method utilizes the fact that the Gini coefficient $G$ is additively decomposable by the $K$ assets and liability sources:

\footnotetext{
${ }^{21}$ Appendix Table A2 presents values of equity in closely held firms and unincorporated businesses distributed according to different assumed schemes across top fractiles in the wealth distribution. Assuming constant ranks in the distribution, adding the value of this unlisted equity raises - in the most unequal scenario - the share of financial assets in the top 0.1 percentile from $1 / 3$ to $2 / 3$. Less unequal scenarios imply less of a difference.
} 
$G=\sum_{k=1}^{K} S_{k} G_{k} R_{k}$, where $S_{k}$ is the share of the $k$ th wealth component in total wealth, $G_{k}$ its degree of dispersion, and $R_{k}$ the Gini correlation ratio with total wealth. ${ }^{22}$ From this equation, we compute $k$ 's share of wealth inequality $I_{k}=S_{k} G_{k} R_{k}$.

Figure 11 presents the results for $I_{k}$ across six components when decomposing the net wealth Gini coefficient (see detailed results in Appendix table A3). Real estate stands for the largest contribution of roughly two thirds, but with a slightly decreasing trend. Bank deposits became more unequally held and also more correlated with the rest of wealth, and thus contributes to the increase in overall Gini. We cannot fully account for all reasons, but since the sum of bank deposits did not change this indicates a simultaneous increase in bank savings in the top of the distribution and decrease in the bottom of the distribution. Possibly, lower bank savings among poorer groups could be due to income shocks caused by the crisis while increased bank savings among the rich could be due to portfolio reallocation from risky to safe assets as a consequence of the financial turbulence. Apartment ownership also contributed to the increased inequality, but not because these have become more unequally held, but because their aggregate share of all of household wealth has increased following a period of substantial house price increases over the past years. Neither corporate equity nor mutual fund ownership contributed much to the change in wealth inequality. Bank debt, finally, was slightly disequalizing until 2009 but slightly equalizing afterwards.

[Figure 11 about here]

\section{International comparison}

How do the recent Swedish wealth inequality trends compare with the experiences of other Western countries? Are they part of a broader, international pattern or does Sweden stand out in this respect? Unfortunately there is only scarce evidence on wealth inequality trends in the Western world over the recent period. ${ }^{23}$ The few studies that exist have focused primarily on various aspects of how wealth dispersion has changed during the Great Recession. In their studies of the German experience, Grabka and Westermeier (2014) and Grabka (2015) report levels and dispersion of wealth in a nationally representative sample of German households in

\footnotetext{
${ }^{22}$ The Gini correlation ratio is calculated as the covariance of wealth source $k$ and the cumulative distribution of total wealth divided by the covariance of wealth source $k$ and its own cumulative distribution.

${ }^{23}$ For a recapitulation of the trends in wealth concentration in Western countries over the very long run, see Roine and Waldenström (2015).
} 
various years just before and after the crisis. For the United States there are two different sources that have generated studies. A number of studies employ evidence in the Survey of Consumer Finances (SCF) that is available for several years before the Great Recession and with latest observation in 2013. Examples of such studies are Wolff $(2013,2015)$ and Bricker et al. (2015) who report Gini coefficients and top wealth shares. In addition, Saez and Zucman (2016) estimate, as we have already discussed, annual top wealth shares for the U.S. since the beginning of the twentieth century up until 2012 using capitalized capital income statements in tax returns adjusted with Financial Accounts aggregates and Forbes wealth data.

It should be noted that the comparability of the studies from Germany, Sweden and the U.S. is far from perfect, which primarily is explained by the differing nature of the wealth data used. While the German and U.S. SCF studies rely on wealth survey evidence in representative samples, the present and Saez and Zucman studies use capitalized incomes stemming mainly from income tax registers. However, as noted above the two capitalization studies also differ between them in several aspects (e.g., whether to include estimates of wealth in non-listed business equity or defined-contribution pension plans).

Table 2 presents wealth inequality in Germany, Sweden and the U.S., captured using various measures of dispersion, in two recent years for which observations exist in all countries: 2007 and 2012 (2013 for the SCF). According to these estimates, that has been no uniform development across Western countries in wealth concentration around the time of the Great Recession. The Gini coefficient remained largely stable in Germany (an insignificant decrease from 0.799 to 0.780 ) but increased in Sweden from 0.835 to 0.943 and in the U.S. from 0.834 to 0.871. Looking at the P90/P50 ratio, there is a slight reduction in wealth concentration in Germany but in contrast substantial increases in both Sweden and the U.S. In the Swedish case we have pointed to the importance of bank deposits and house prices that diverged across the middle and the top during these years. In the U.S. case, the development is primarily driven by a large drop in median wealth which Wolf (2014) refers to as an asset-price "meltdown” in the housing market.

Turning to top wealth shares, the pattern is the same. In Germany, the top percentile's share of total wealth fell by about one tenth (from 21.7 percent to 18.7 percent) whereas it increased slightly in Sweden (from 19.2 to 21.7 percent) and somewhat more in the U.S., by six percent (from 34.6 to 36.7 percent) according to the SCF and by 16 percent (from 36 to 41.8 percent) 
according to Saez and Zucman. The difference between the SCF survey evidence and the estimated capitalized wealth incomes of Saez and Zucman has several sources, but the main difference according to a comparative analysis by Bricker et al. (2015) is related to the treatment of housing assets and extreme family wealth of the richest Americans. ${ }^{24}$

[Table 2 about here]

Altogether, the comparison of the recent trends in personal wealth dispersion before and after the Great Recession in Germany, Sweden and the U.S. does not indicate any strong similarity across the Western world. While inequality appears to have increased (moderately) in Sweden and the U.S., it has remained stable in Germany. The evidence is admittedly coarse and the comparability imperfect, but the heterogeneity in both levels and trends over this period suggest that country-specific factors matter a lot to the evolution of wealth inequality.

\section{Concluding remarks}

The question we set out to answer in this study is how the Swedish personal wealth distribution has evolved since 2007. This year, a right-wing party alliance was elected after a long period of Social Democratic rule and among its first reforms was to repeal the wealth tax, a measure that among other things effectively dismantled official individual wealth statistics. No one has since then been able to measure wealth inequality in Sweden. Using capitalization techniques to compute financial wealth data and combining this with observed wealth stocks in the property assessments, we have tried to estimate individual wealth levels in the adult population and compute distributional outcomes.

Our main result concerning wealth inequality in Sweden is that it appears to have increased since 2007. The recorded rise in the Gini coefficient and top wealth shares is about ten percent, and almost all of this increase occurred around the years of the financial crisis 20082009. A decomposition analysis shows that it can be attributed primarily to more unequal holdings of apartments and bank savings.

The trustworthiness of capitalized wealth data for distributional analyses is central for this

\footnotetext{
${ }^{24}$ For a thorough discussion of the differences between these sources and the implications for estimating wealth inequality, see also Saez and Zucman (2014), Bricker et al. (2014) and Kopczuk (2015).
} 
conclusion. We compare our estimated wealth series, based on both observed and capitalized stocks, with the register-based wealth levels and find both cases of high consistency and instances of large deviations. The goodness-of-fit increases in the detail of the income flow data. For example, when we observe firm-specific dividends we are able to estimate the value of corporate shares with high precision. By contrast, estimating the value of bank holdings and bank debt using composite interest income and aggregate interest yields produces fairly poor fits throughout. Overall, our estimated wealth inequality trends are positively correlated with those observed in the registers, but the fit of levels varies between assets.

Looking ahead, our investigation has pointed to a need to make further inquiries into the structure and change of Swedish wealth inequality. We are currently limited by the fact that Swedish registers do not cover all private assets, most importantly the equity of non-listed firms, including holdings of private equity funds among a specific segment in the financial industry, and savings in funded pension schemes, which together represent approximately one fifth of all household wealth. It is a priori not obvious how this measurement problem affects our findings, since non-listed corporate stock is probably more skewed than non-equity wealth while occupational pension wealth may well be more equally divided than other assets. Adding these, and other, missing data points would not only improve the measurement of wealth inequality but also offer further insights into the role of institutions, e.g., how social insurance or pensions influence individuals' willingness to privately accumulate capital. While it is beyond the scope of the present study to make such extensions they are the kind of examinations that should be given priority in future investigations. 


\section{References}

Atkinson, A. B., J. A. Harrison (1978). The Distribution of Personal Wealth in Britain, Cambridge: Cambridge University Press.

Bach, L., L. Calvet, P. Sodini (2015). "Rich Pickings? Risk, Return, and Skill in the Portfolios of the Wealthy.” Mimeo, Swedish House of Finance, Stockholm School of Economics.

Bricker, J., L. J. Dettling, A. Henriques, J. W. Hsu, K. B. Moore, J. Sabelhaus, J. Thompson, R. A. Windle (2014). "Changes in U.S. Family Finances from 2010 to 2013: Evidence from the Survey of Consumer Finances.” Federal Reserve Bulletin, 100(4).

Bricker, J. A. M. Henriques, J. A. Krimmel, J. E. Sabelhaus (2015). “Measuring Income and Wealth at the Top Using Administrative and Survey Data." Finance and Economics Discussion Series 2015-030. Washington: Board of Governors of the Federal Reserve System.

Cowell, F. A. (2013). "UK Wealth Inequality in International Context." in Hills, J. (ed.) Wealth in the UK, Oxford: Oxford University Press.

Cowell, F., P. Van Kerm (2015). "Wealth Inequality: A Survey.” Journal of Economic Surveys 29(4): 671-710.

Du Rietz, G., M. Henrekson (2015). “Swedish Wealth Taxation (1911-2007).” in Magnus Henrekson, Mikael Stenkula, eds., Swedish Taxation: Developments Since 1862. New York: Palgrave Macmillan.

Fagereng, A., L. Guiso, S. Mancredo, L. Pistaferri (2016). "Heterogeneity in Returns to Wealth and the Measurement of Wealth Inequality.” American Economic Review Papers \& Proceedings, in press.

Grabka, M. K (2015). "Income and wealth inequality after the financial crisis: the case of Germany.” Empirica, 42: 371-390.

Grabka, M. K, C. Westermeier (2014). "Persistently High Wealth Inequality in Germany.” DIW Economic Bulletin, No. 6.

Kopczuk, W. (2015). "What Do We Know About the Evolution of Top Wealth Shares in the United States?” Journal of Economic Perspectives 29(1): 47-66.

Kopczuk, W., E. Saez (2004). “Top Wealth Shares in the United States, 1916-2000: Evidence from Estate Tax Returns.” National Tax Journal 52: 445-487.

Lerman, R. I., S. Yitzhaki (1985). “Income Inequality Effects by Income.” The Review of Economics and Statistics 67(1): 151-156.

OECD (2015). In It Together: Why Less Inequality Benefits All, OECD: Paris.

Roine, J., D. Waldenström (2009). "Wealth Concentration over the Path of Development: Sweden, 1873-2006.” Scandinavian Journal of Economics 111(1): 151-187. 
Roine, J., D. Waldenström (2015). "Long run trends in the distribution of income and wealth”, in: A.B. Atkinson \& F. Bourguignon (Eds.), Handbook of Income Distribution, vol. 2, North-Holland: Amsterdam.

Saez, E., G. Zucman (2016). "Wealth Inequality in the United States since 1913: Evidence from Capitalized Income Tax Data.” Quarterly Journal of Economics, forthcoming.

Shorrocks, A. F. (1978). “The Measurement of Mobility.” Econometrica 46(5): 1013-1024.

Statistics Sweden (2007). Förmögenhetsstatistik 2007. HE0104_DO_2007, Statistiska centralbyrån.

Statistics Sweden (2010). Förstudie över visa skuld- och tillgångsgrupper. Dnr 2012/1504, Statistiska centralbyrån

Statistics Sweden (2012). Förmögenhetsstatistikens framtid. Utredning av alternativa registerkällor till SCB:s individbaserade förmögenhetsstatistik. Dnr 2010/0858, Statistiska centralbyrån

Waldenström, D. (2016). “The National Wealth of Sweden, 1810-2014.” Scandinavian Economic History Review, in press.

Wolff, E. N. (2013). “The Asset Price Meltdown, Rising Leverage, and the Wealth of the Middle Class.” Journal of Economic Issues 47(2): 333-342.

Wolff, E. N. (2015). "Household Wealth Trends in the United States, 1962-2013: What Happened Over The Great Recession?.” NBER Working Paper No. 20733. 
Figure 1: Rate of return over asset amounts (Euros).

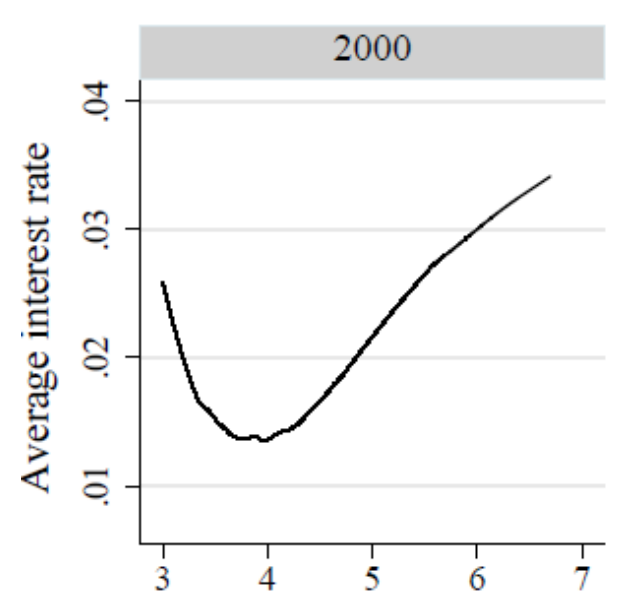

a) Bank deposits
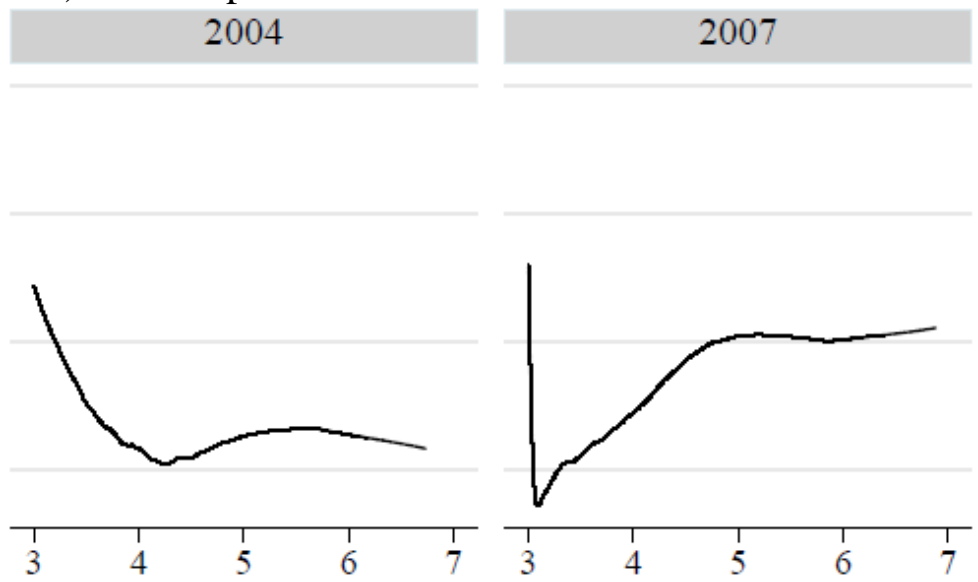

10-logarithm of bank deposits

b) Corporate shares
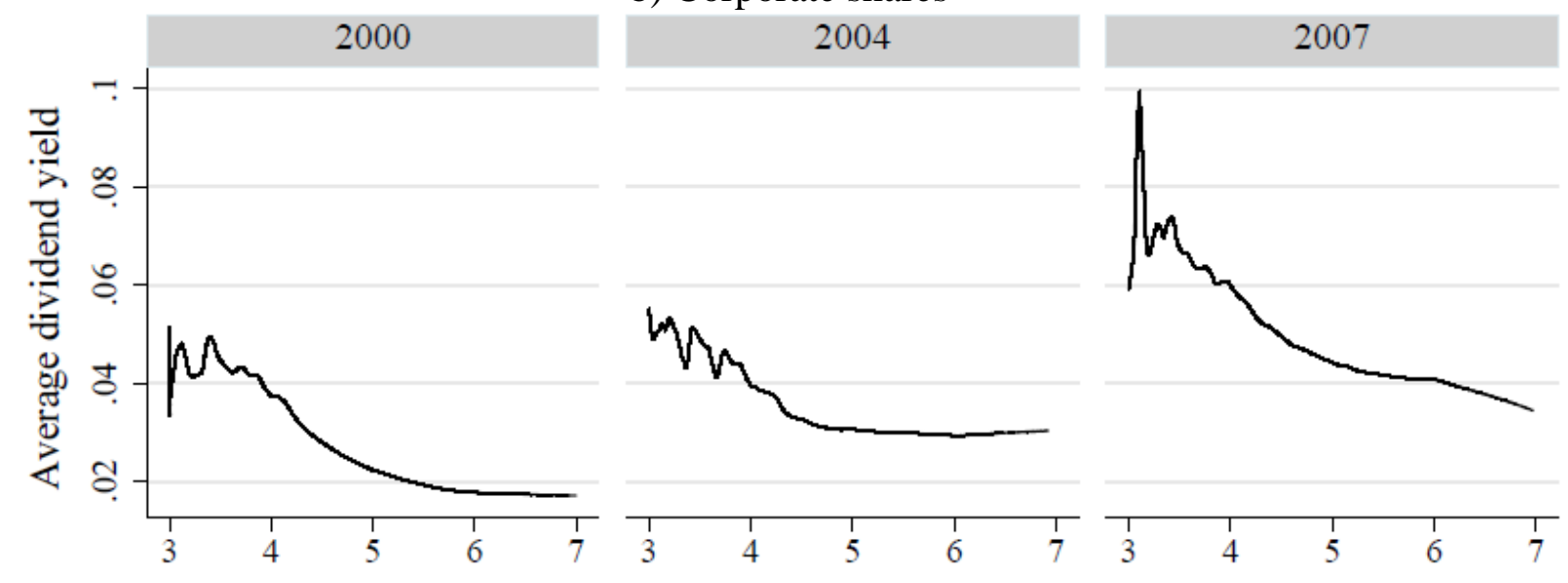

10-logarithm of stock holdings

c) Bank debt
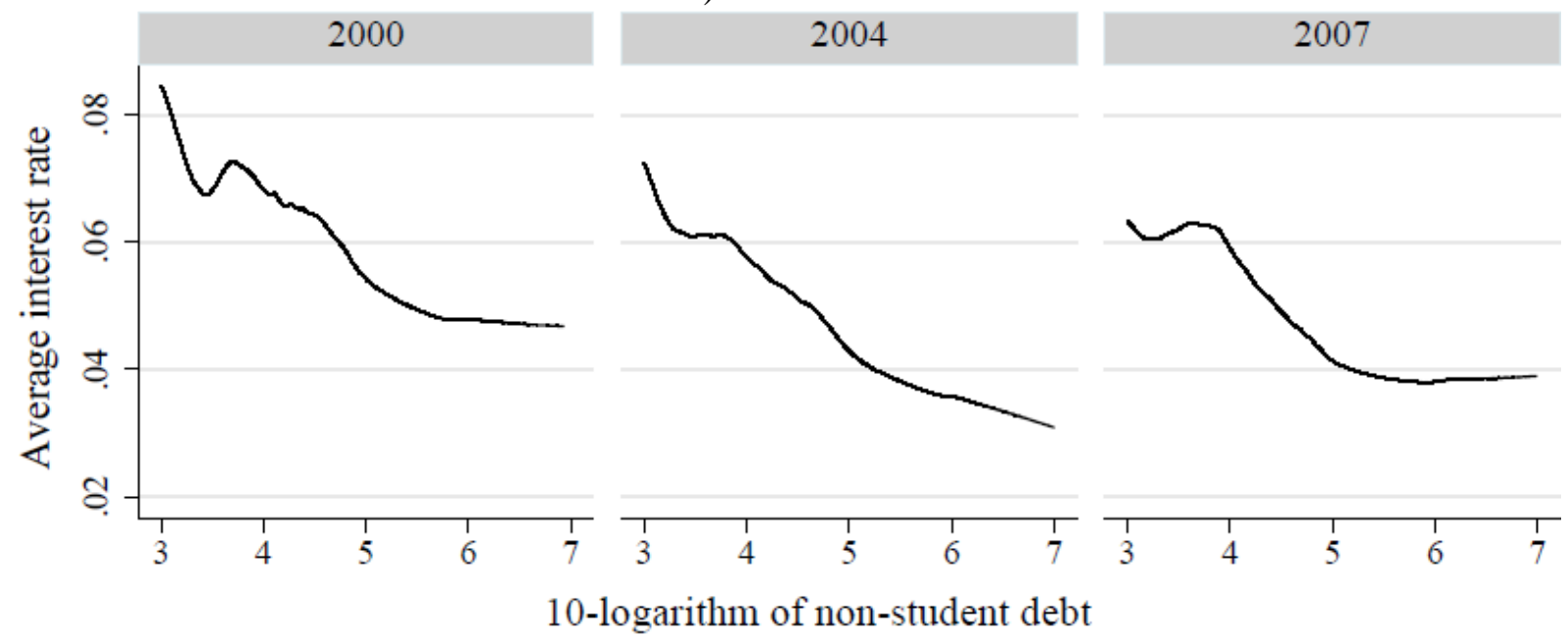

Note: The graphs show local regressions over adult (20+) individuals for average yields (y-axis) over the held asset or debt amounts (x-axis). See text for further details. 
Figure 2: Rates of return across fractiles in the distribution.
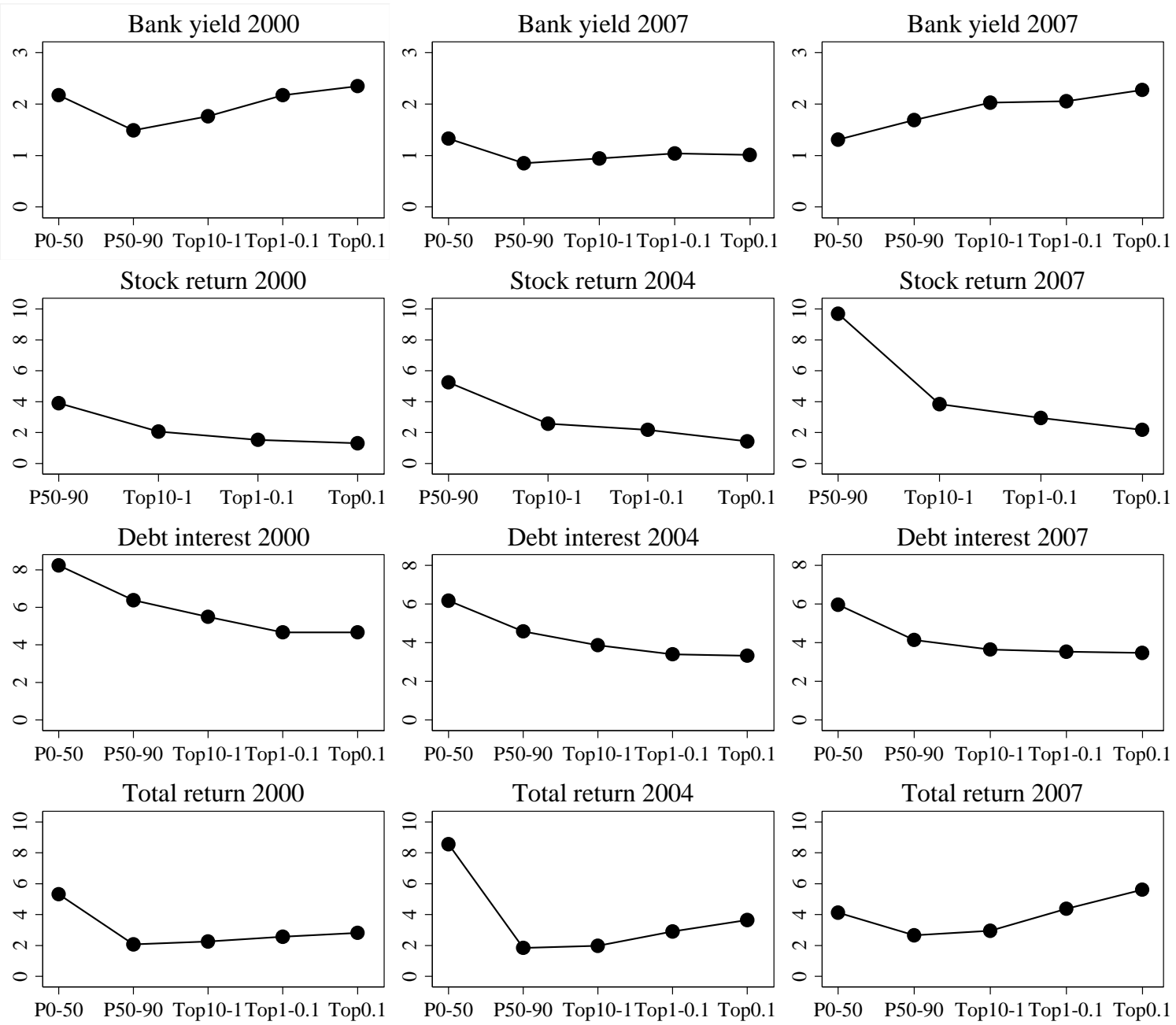

Note: Returns and interest expenses in percent of the respective stocks, contingent on holding positive amounts. 
Figure 3: Goodness-of-fit of capitalized wealth by asset classes in 2007.

a) Real estate

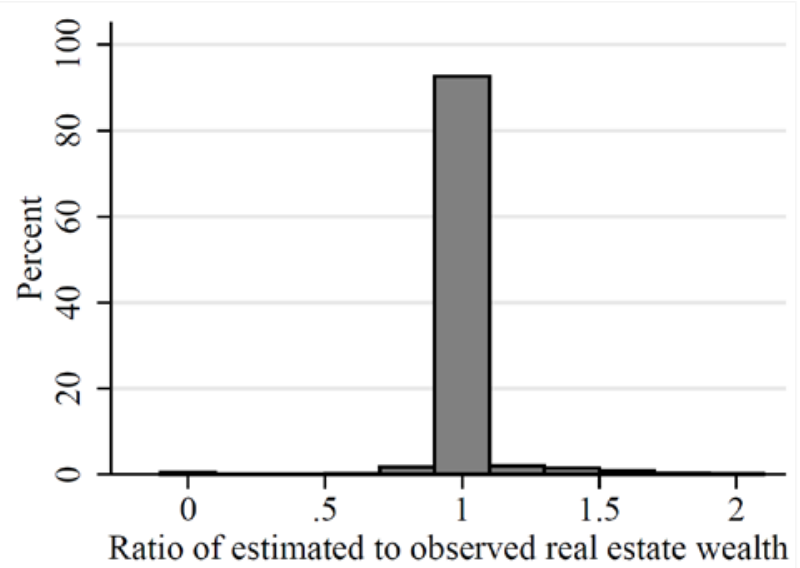

c) Corporate shares

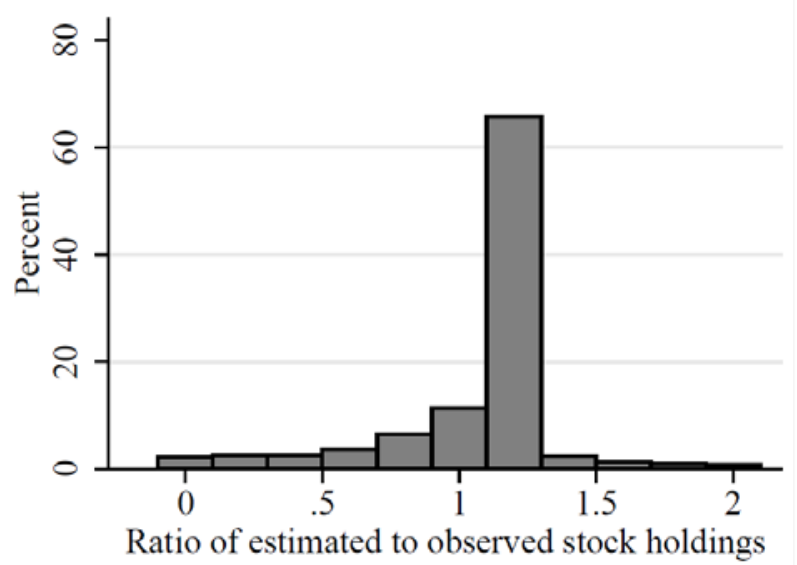

e) Bank debt

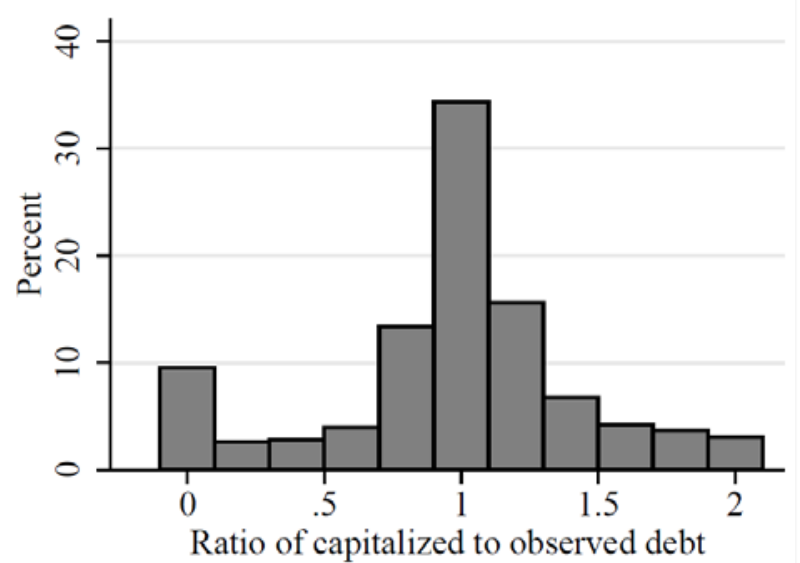

b) Bank deposits

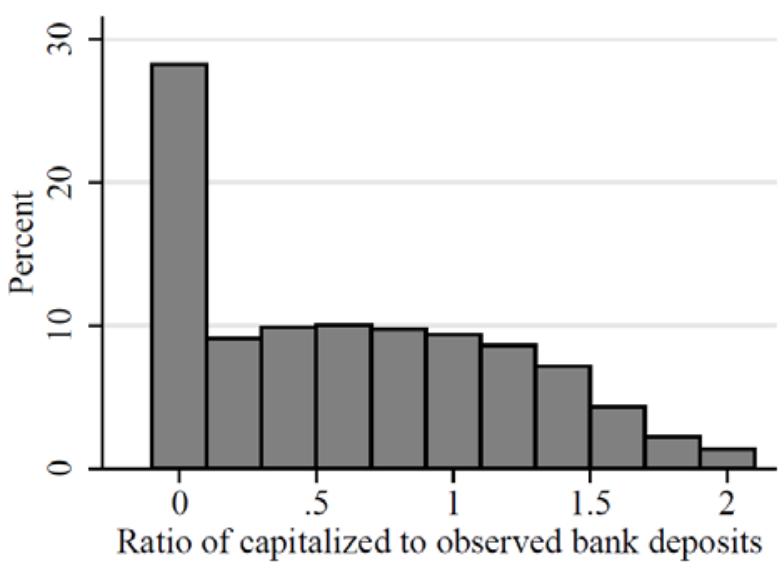

d) Gross assets

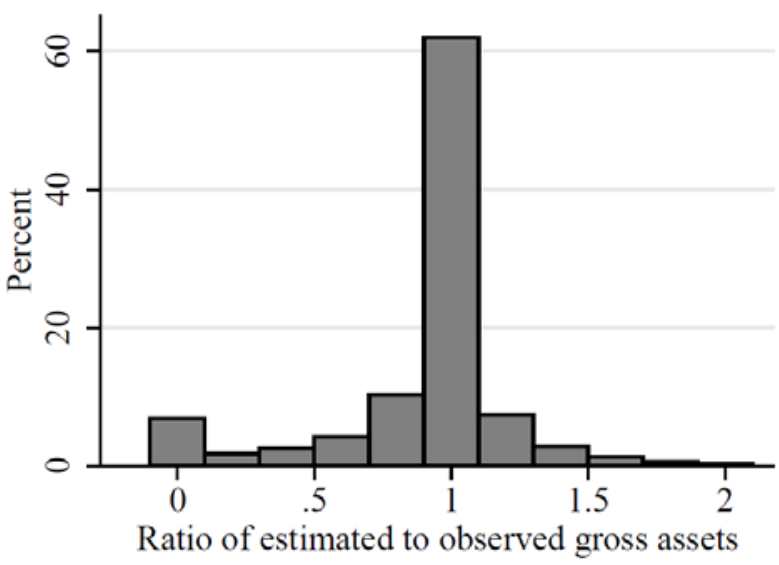

c) Net wealth

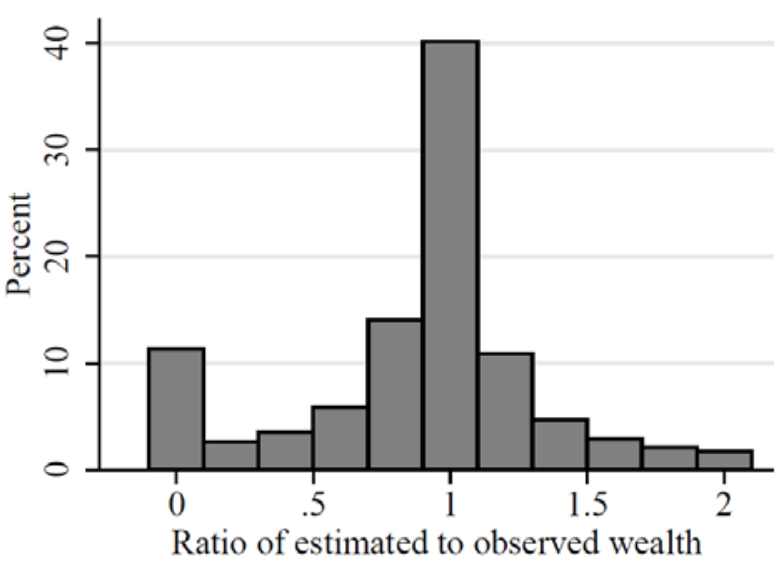

Note: These histograms do not cover the full range of observations as we have restricted them to show ratios between 0 and 2 . The share of observations outside this range varies as follows: real estate $0.3 \%$, bank deposits $6.3 \%$, corporate shares $9.6 \%$, gross wealth $1.9 \%$, bank debt $20.0 \%$ and net wealth $9.7 \%$. 
Figure 4: Gini coefficients of some assets and debts.
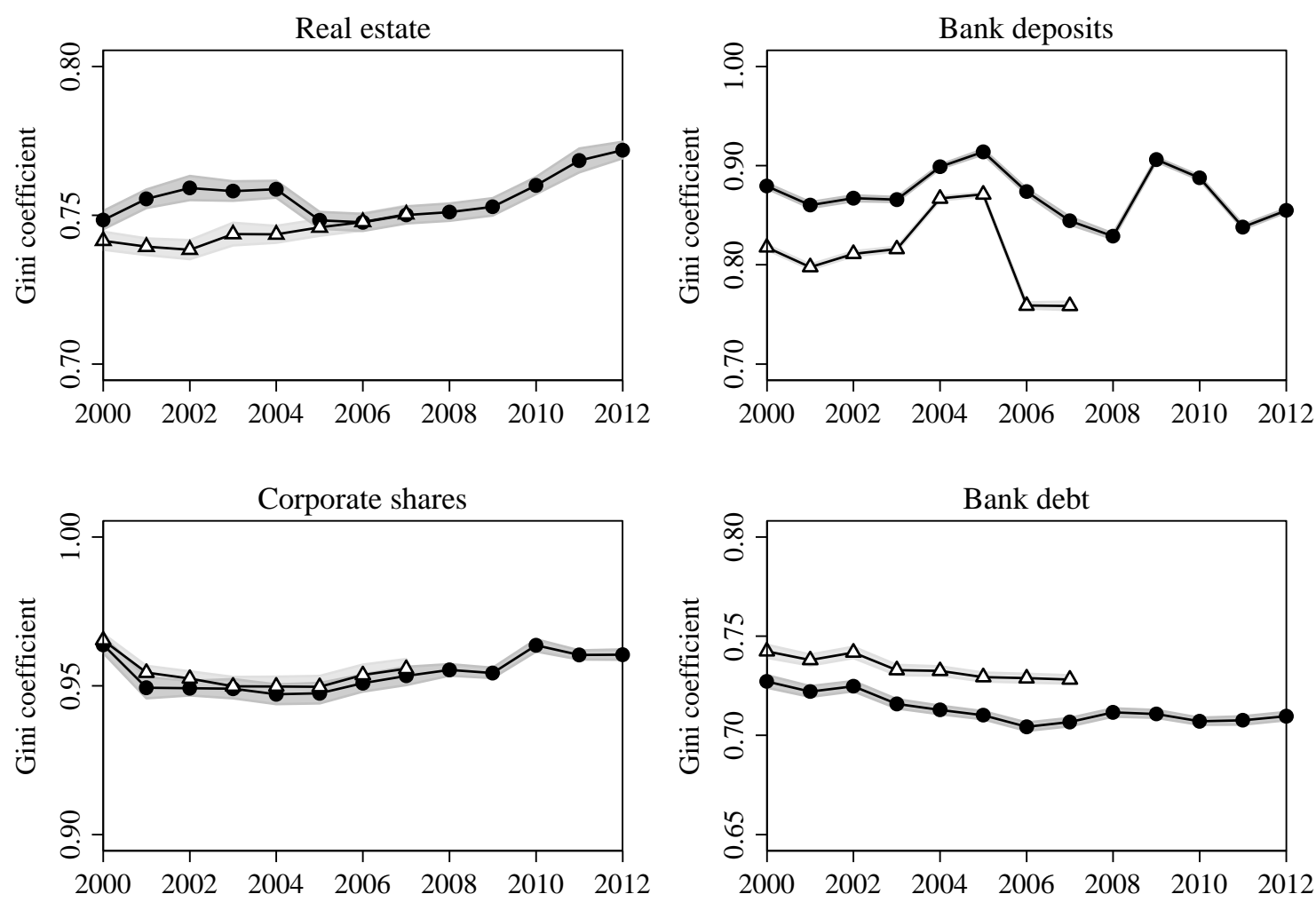

\section{$\multimap-$ New estimates $\quad \backsim$ Wealth Register}

Note: Top wealth shares in the adult (20+) population (LINDA database). "New estimates" denotes the dispersion of adult individual wealth estimated from our hybrid approach combining observed and capitalized wealth stocks as described in text. "Wealth Register" denotes wealth shares from Statistics Sweden's Wealth Register. Data series are from Table A1. 
Figure 5: Gini coefficients of some assets and debts.

a) Gini coefficients

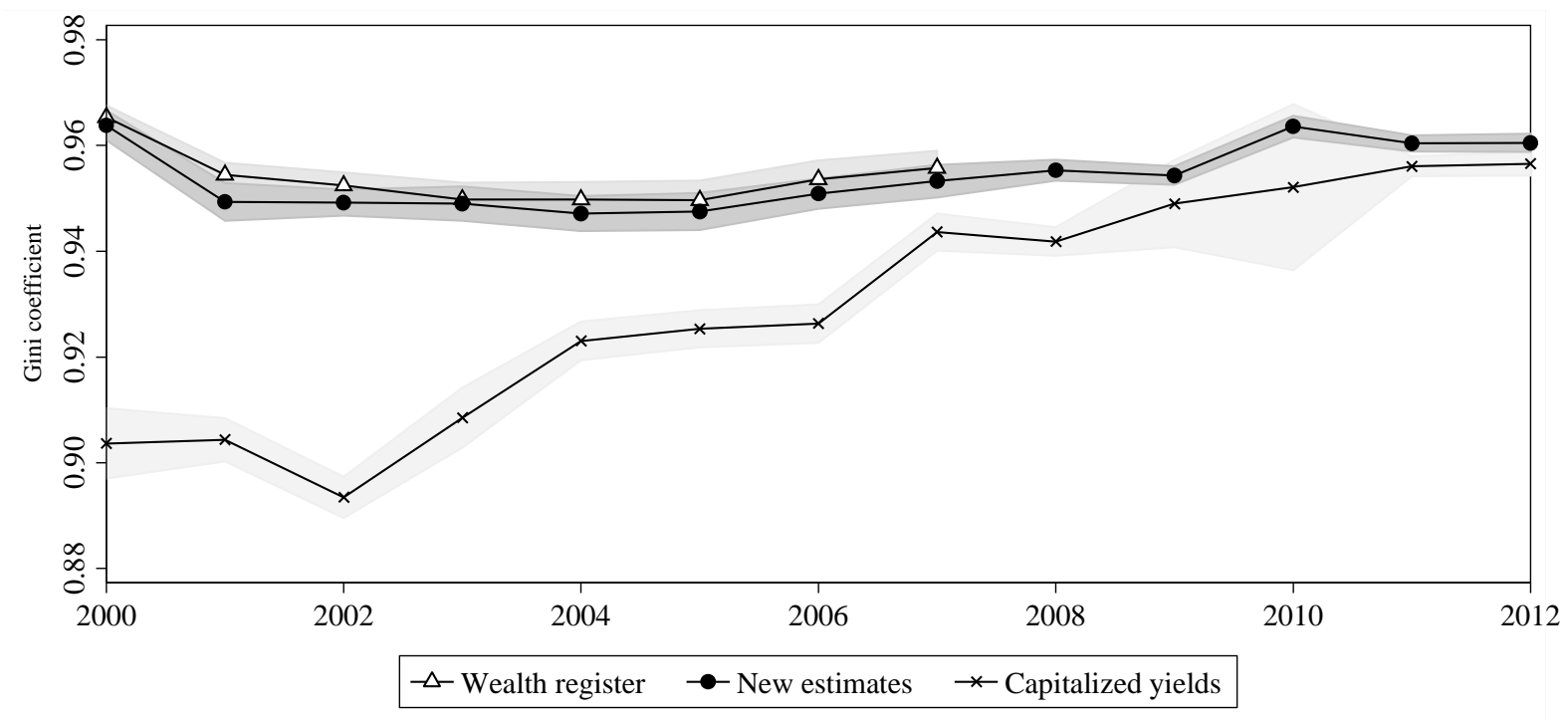

b) Ratio of our estimated to observed stocks

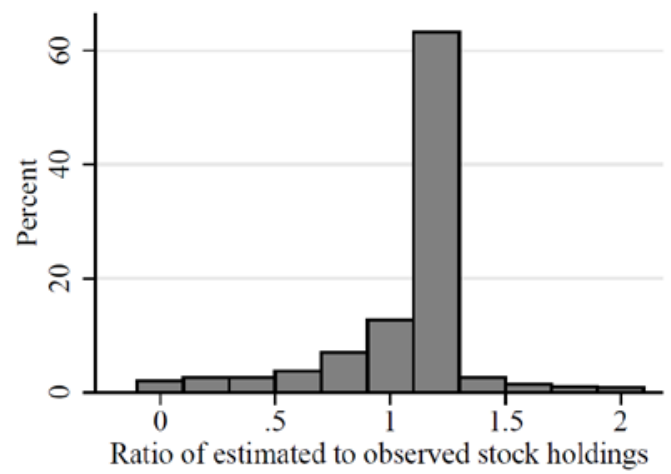

c) Ratio crude capitalization vs. observed

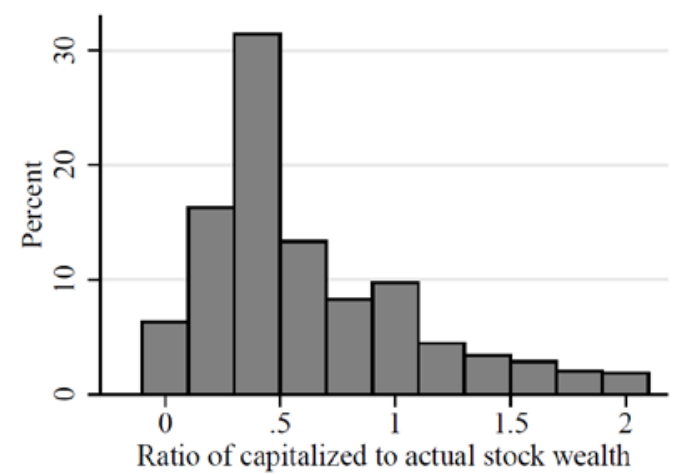

Note: See notes to figures 3 and 4 and the text for further information. 
Figure 6: Average net wealth in deciles, 2000-2012.

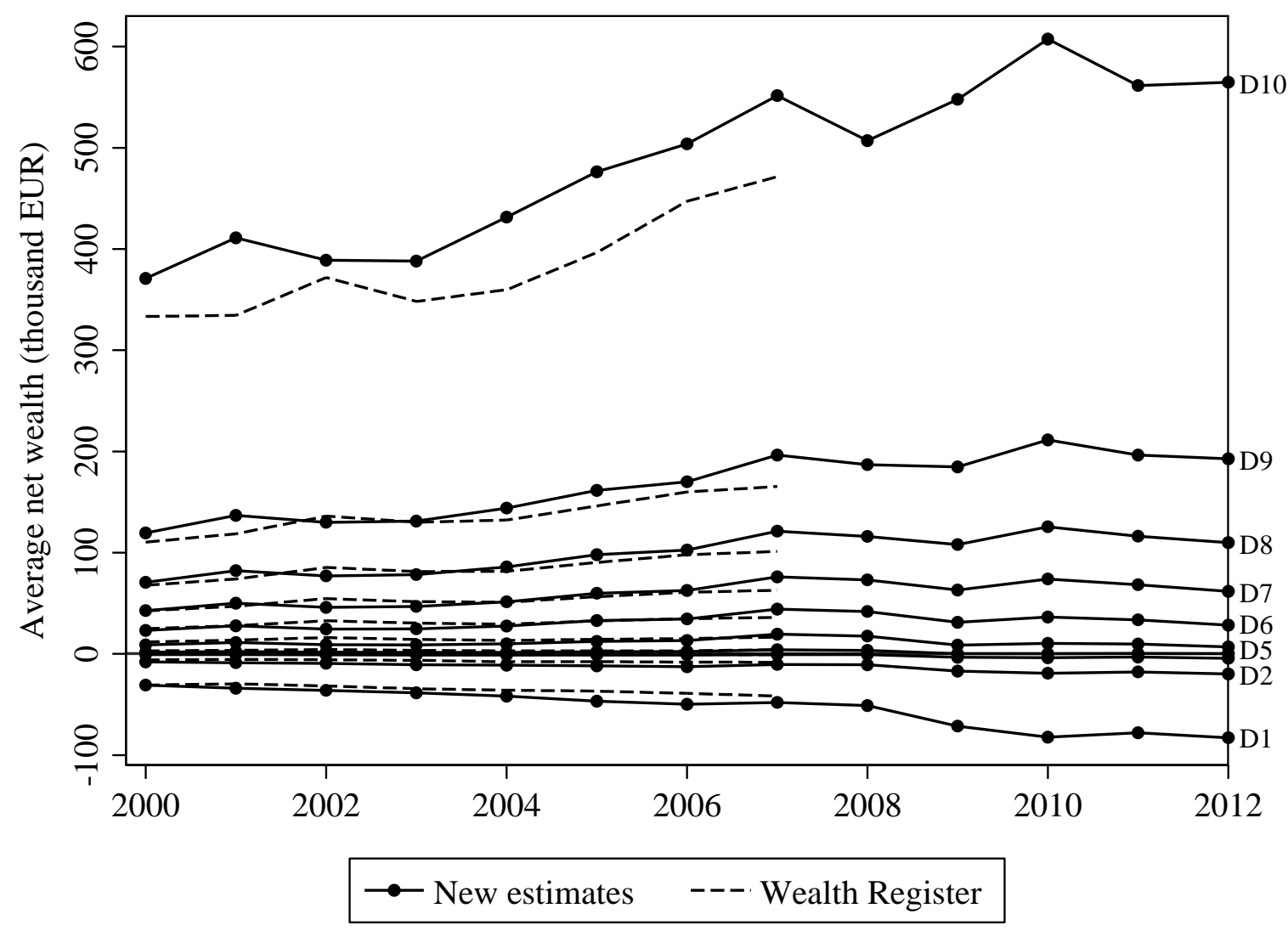

Note: See note to figure 4 and the text for further information. 
Figure 7: Gini coefficient for net wealth in Sweden, 2000-2012.

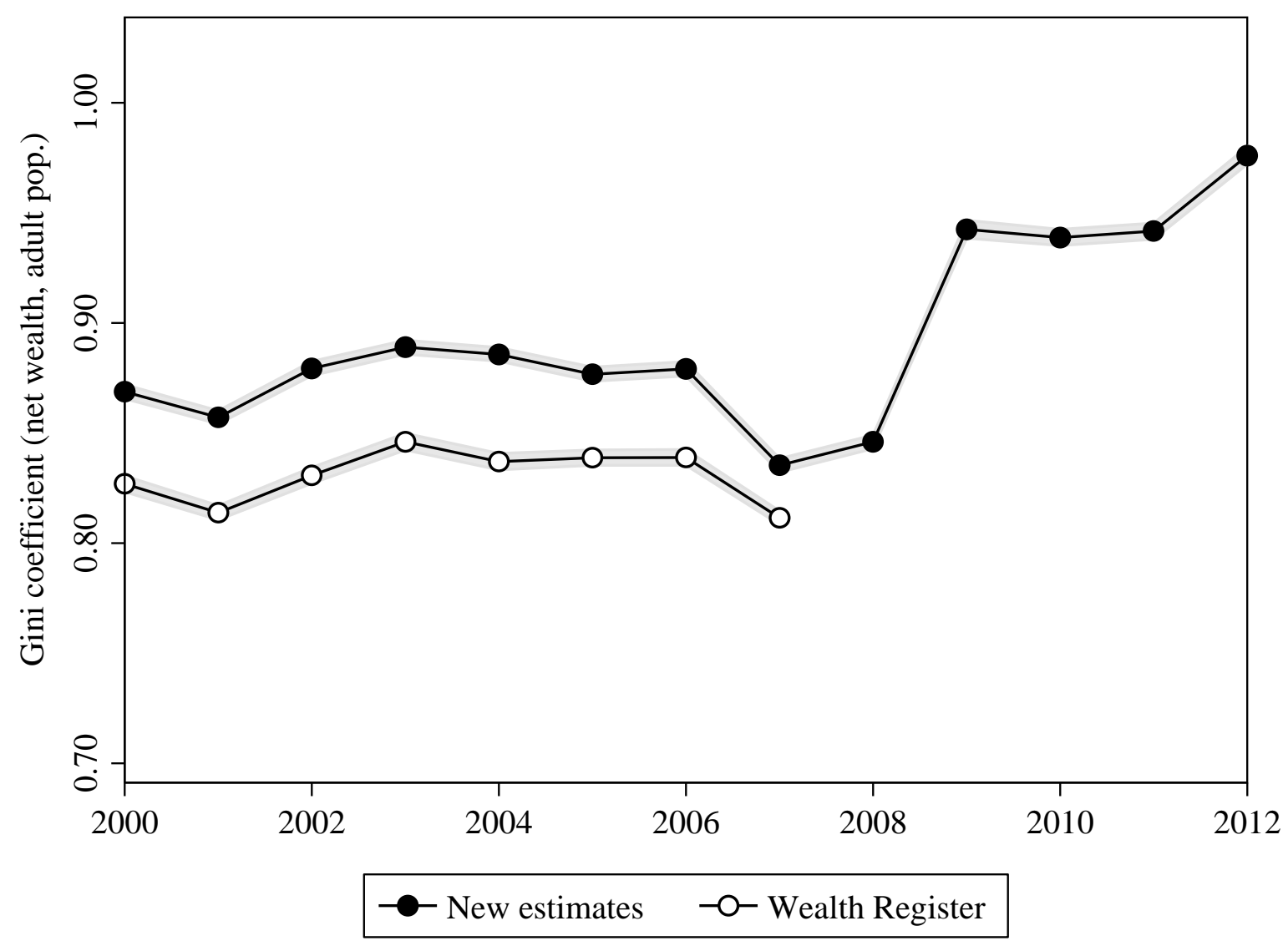

Note: See note to figure 4 and the text for further information. 
Figure 8: Top wealth shares in Sweden, 2000-2012.

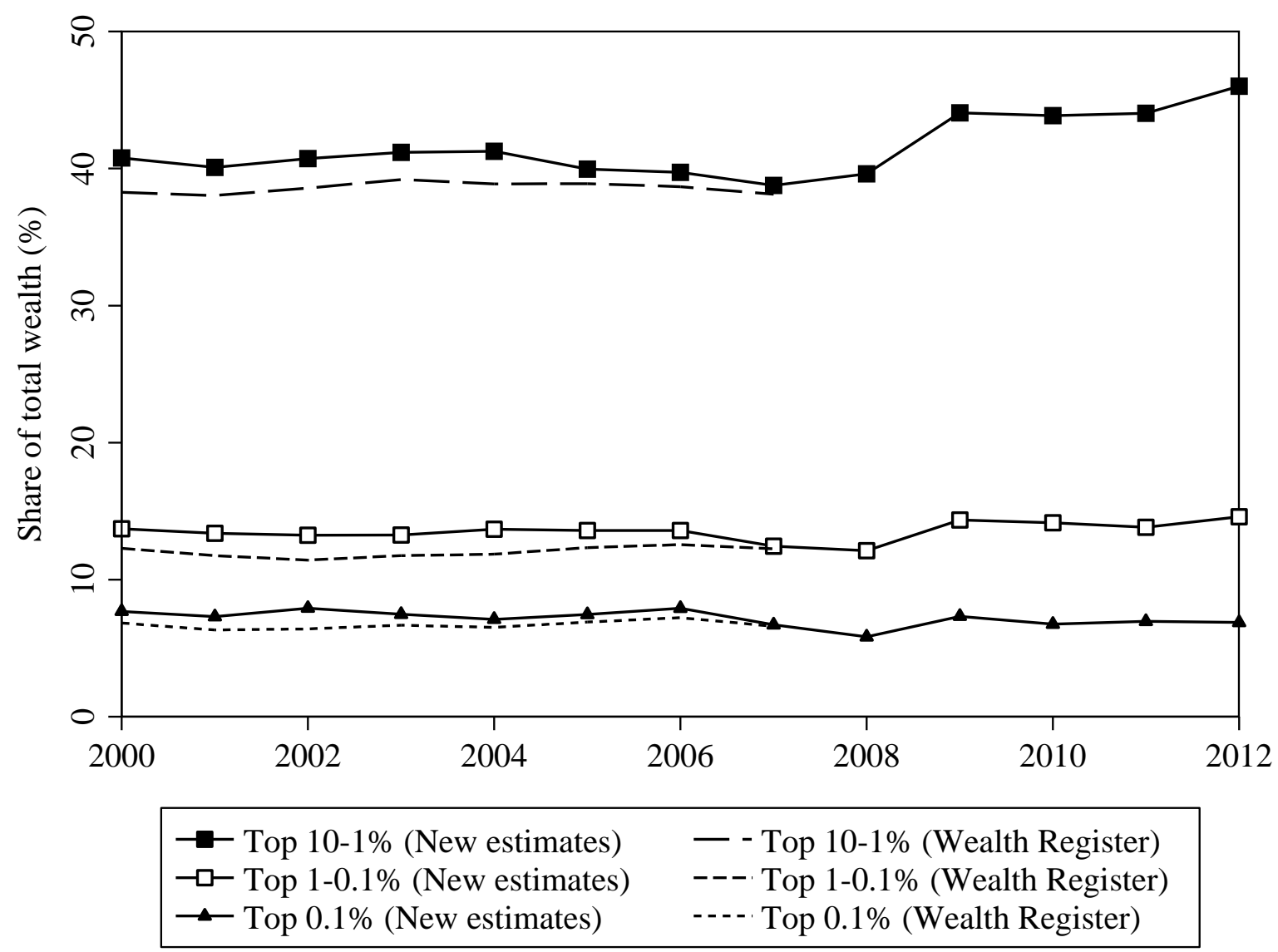

Note: See note to figure 4 and the text for further information. 
Figure 9: Inequality trends in Sweden: Wealth, earnings, disposable income.

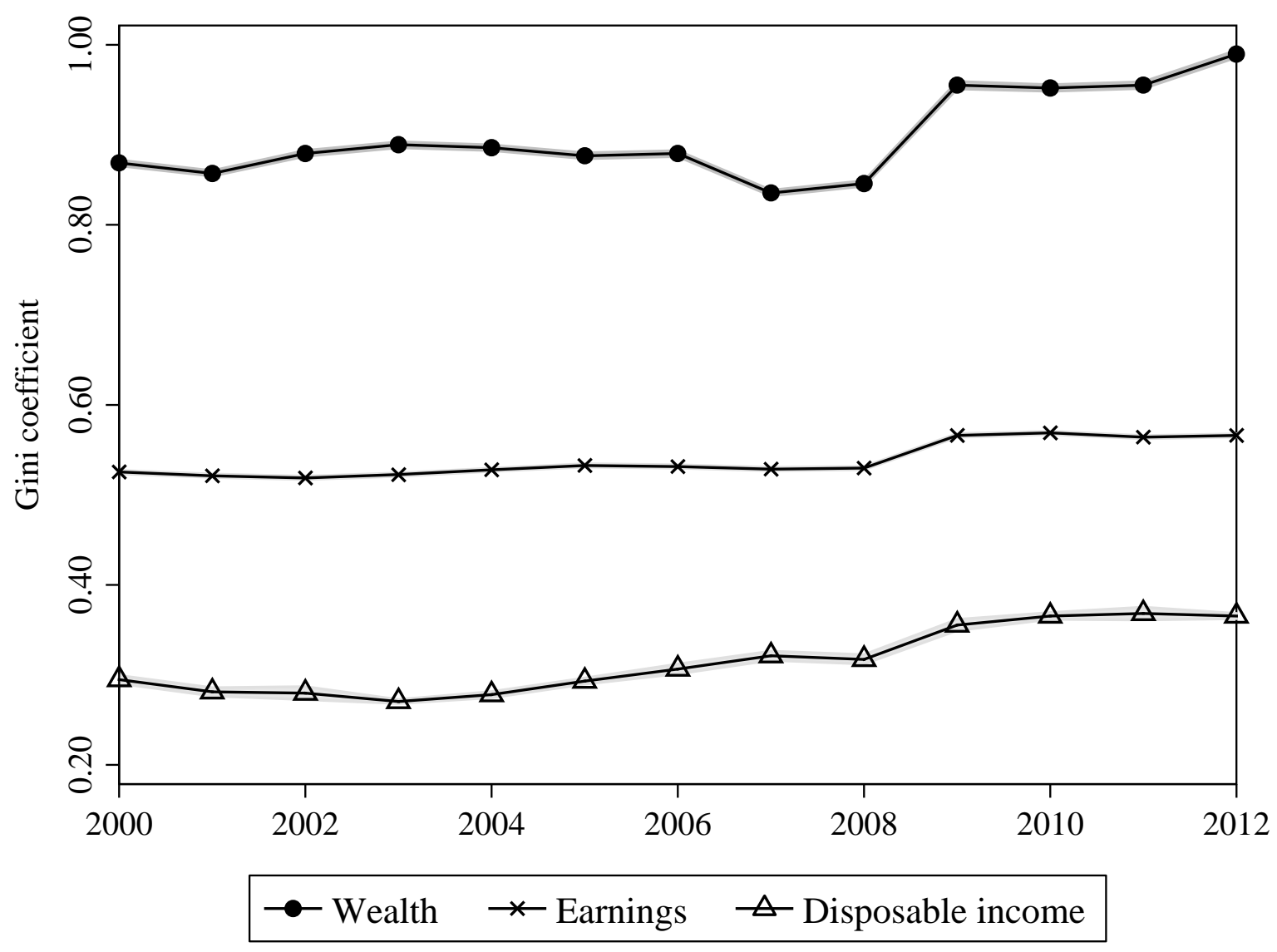

Note: All Gini coefficients are based on the same population of adult (20+) individuals in the LINDA database. "Earnings" contain all labor-related income excluding transfers and social-security related income (e.g., insurance payments and pensions). "Disposable income" contains total income net of direct taxes and transfers. "Wealth" is our estimated wealth. See note to figure 4 and the text for further information. 
Figure 10: Composition of wealth across the Swedish wealth distribution.

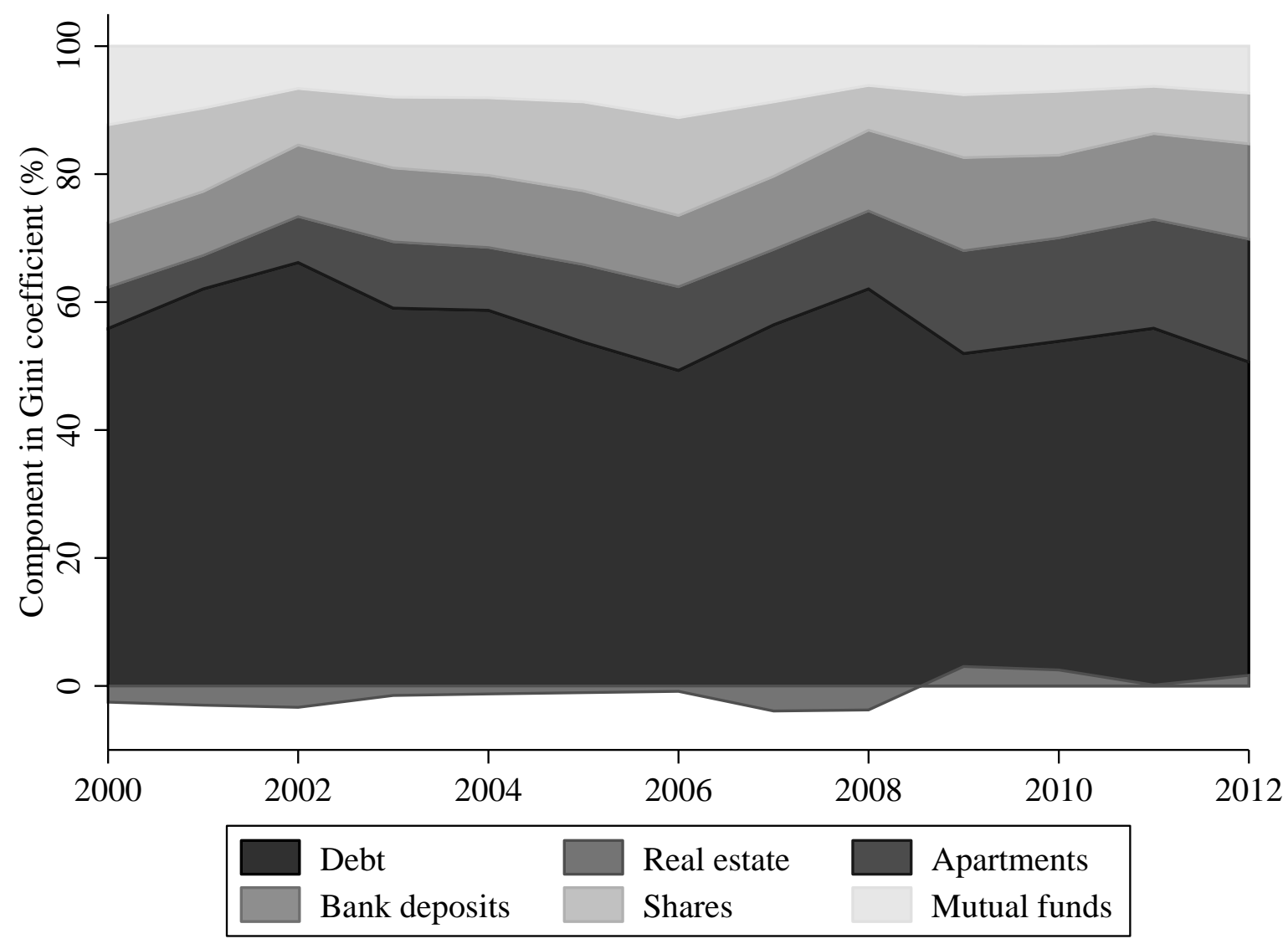


Figure 10: Composition of wealth across the Swedish wealth distribution.
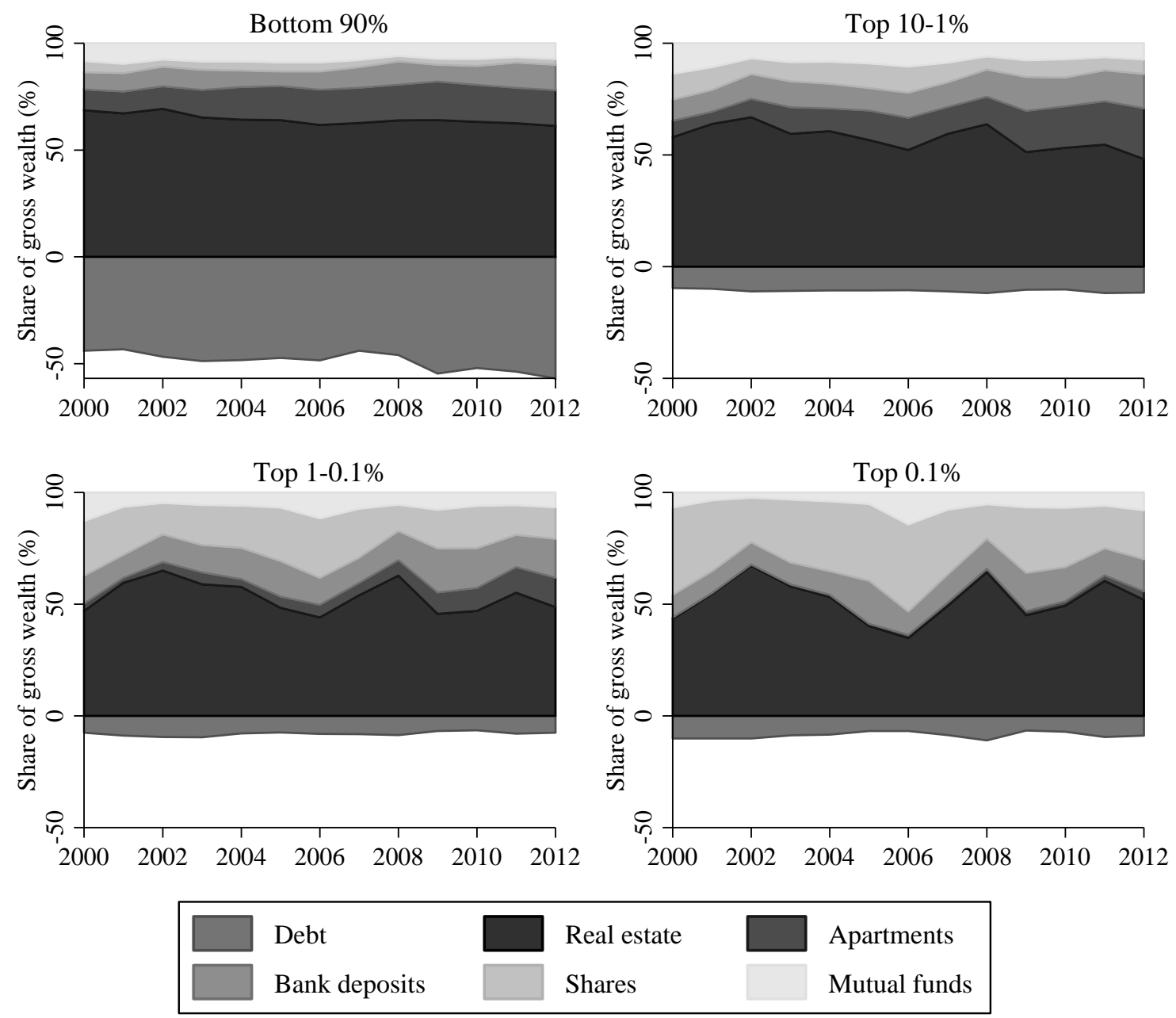

Note: Figures show shares of gross capitalized wealth of different asset categories and debt. See note to figure 4 and the text for further information. 
Figure 11: Decomposition of the Swedish net wealth Gini coefficient, 2000-2012.

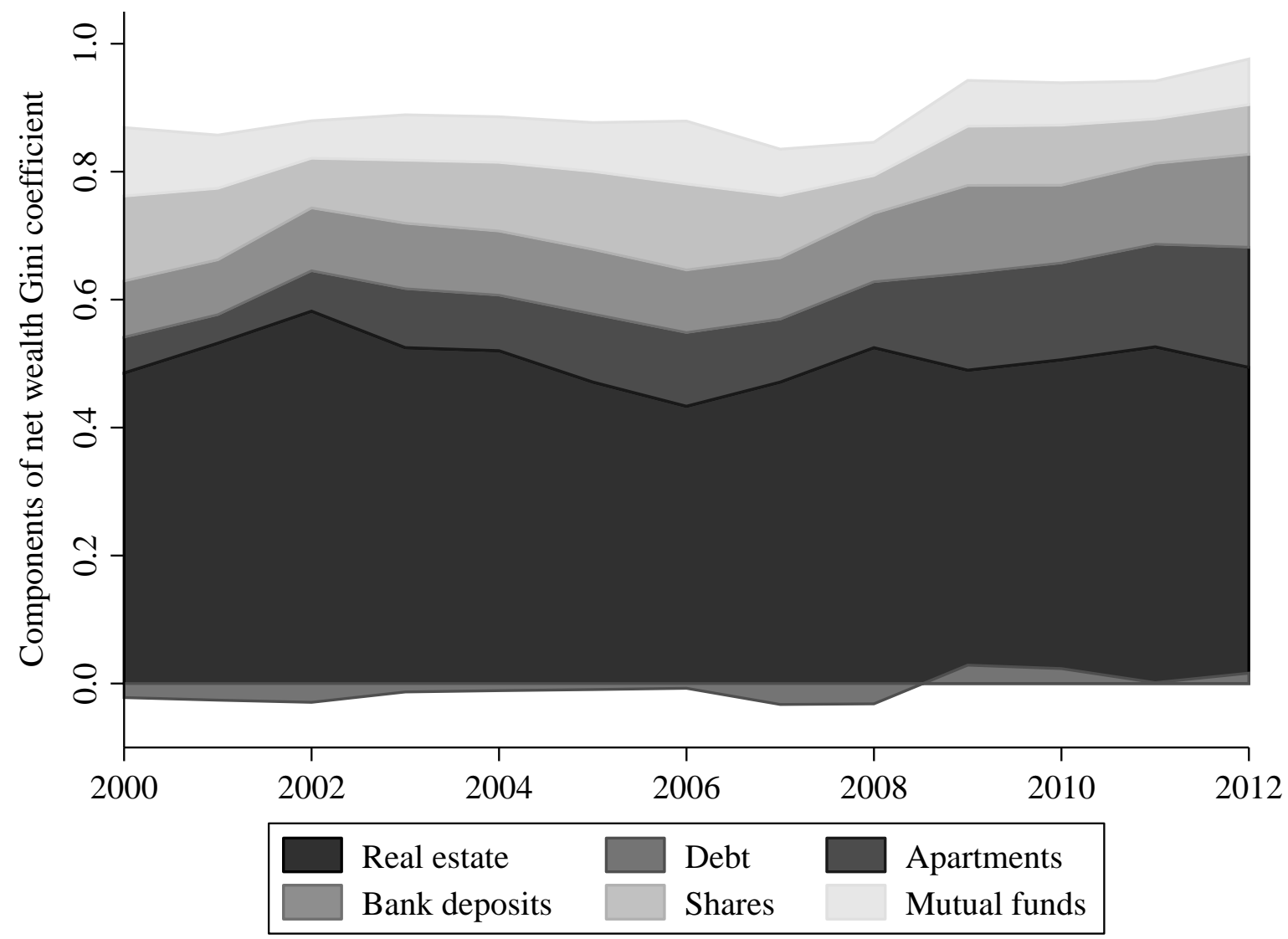

Note: Net wealth Gini decomposition (Lerman and Yithzaki,1985). See text and Appendix table A3 for details. 
Table 1: The distribution of wealth among Swedish adults in 2012.

\begin{tabular}{lcccc}
\hline \hline Wealth group & $\begin{array}{c}\text { Number of } \\
\text { adults }\end{array}$ & $\begin{array}{c}\text { Lower wealth } \\
\text { threshold } \\
\text { (Euro) }\end{array}$ & $\begin{array}{c}\text { Average } \\
\text { wealth } \\
\text { (Euro) }\end{array}$ & $\begin{array}{c}\text { Wealth } \\
\text { share (\%) }\end{array}$ \\
\hline Full adult population & $7,601,100$ & & 85,000 & 100.0 \\
Bottom half (P0-50) & $3,800,500$ & & $-21,000$ & -11.7 \\
Upper half less Top 10\% (P50-90) & $3,040,400$ & 15,100 & 98,000 & 45.8 \\
Top 10\% (P90-100) & 760,100 & 260,300 & 564,000 & 65.9 \\
Top 10-1\% (P90-99) & 684,100 & 260,300 & 428,000 & 45.0 \\
Top 1\% (P99-100) & 76,000 & 902,700 & $1,792,000$ & 20.9 \\
Top 1-0.1\% (P99-99.9) & 68,400 & 902,700 & $1,353,000$ & 6.7 \\
Top 0.1\% (P99.9-100) & 7,600 & $2,798,400$ & $5,764,000$ & 14.2 \\
\hline \hline
\end{tabular}

Note: Based on the adult (20+) population of individuals in the LINDA database. The concept of wealth in the table is net wealth (total assets minus debts). Wealth consists of our estimated wealth as described in the text. 
Table 2: Wealth inequality changes during the Great Recession, three countries

\begin{tabular}{lccccc}
\hline \hline & & \multirow{2}{*}{ Germany } & Sweden & \multicolumn{2}{c}{ United States } \\
\cline { 5 - 6 } Gini & 2007 & 0.799 & 0.835 & 0.834 & \\
& 2012 & 0.780 & 0.943 & 0.871 & \\
& Change & $-2.4 \%$ & $12.8 \%$ & $4.4 \%$ & \\
\hline P90/P50 & 2007 & 14.0 & 8.3 & 7.9 & \\
& 2012 & 13.0 & 13.9 & 14.8 & \\
& Change & $-7.1 \%$ & $66.1 \%$ & $86.8 \%$ & \\
\hline Top 10-1\% & 2007 & 39.2 & 38.8 & 38.5 & 35.7 \\
& 2012 & 38.8 & 44.1 & 40.4 & 35.4 \\
& Change & $-1.0 \%$ & $13.7 \%$ & $4.9 \%$ & $-0.8 \%$ \\
\hline Top 1\% & 2007 & 21.3 & 19.2 & 34.6 & 36.0 \\
& 2012 & 18.7 & 21.7 & 36.7 & 41.8 \\
& Change & $-12.2 \%$ & $13.2 \%$ & $6.1 \%$ & $16.3 \%$ \\
\hline Top 0.1\% & 2007 & & 6.7 & & 17.7 \\
& 2012 & & 7.3 & & 22.0 \\
& Change & & $9.4 \%$ & & $24.5 \%$ \\
\hline \hline
\end{tabular}

Sources: Germany: Grabka and Westermeier (2014, Table 1), Grabka (2015, Table 2); Sweden: our estimates; United States: "Survey" is based on Survey of Consumer Finances (Wolff, 2015, Table 2) and "Capitalized" is based on Saez and Zucman (Saez and Zucman, 2016, Appendix Tables B1, B2). 


\section{Appendix A Appendix figures and tables}

Figure A1a: Asset yields across the distribution in 2000-2012: Bank deposits
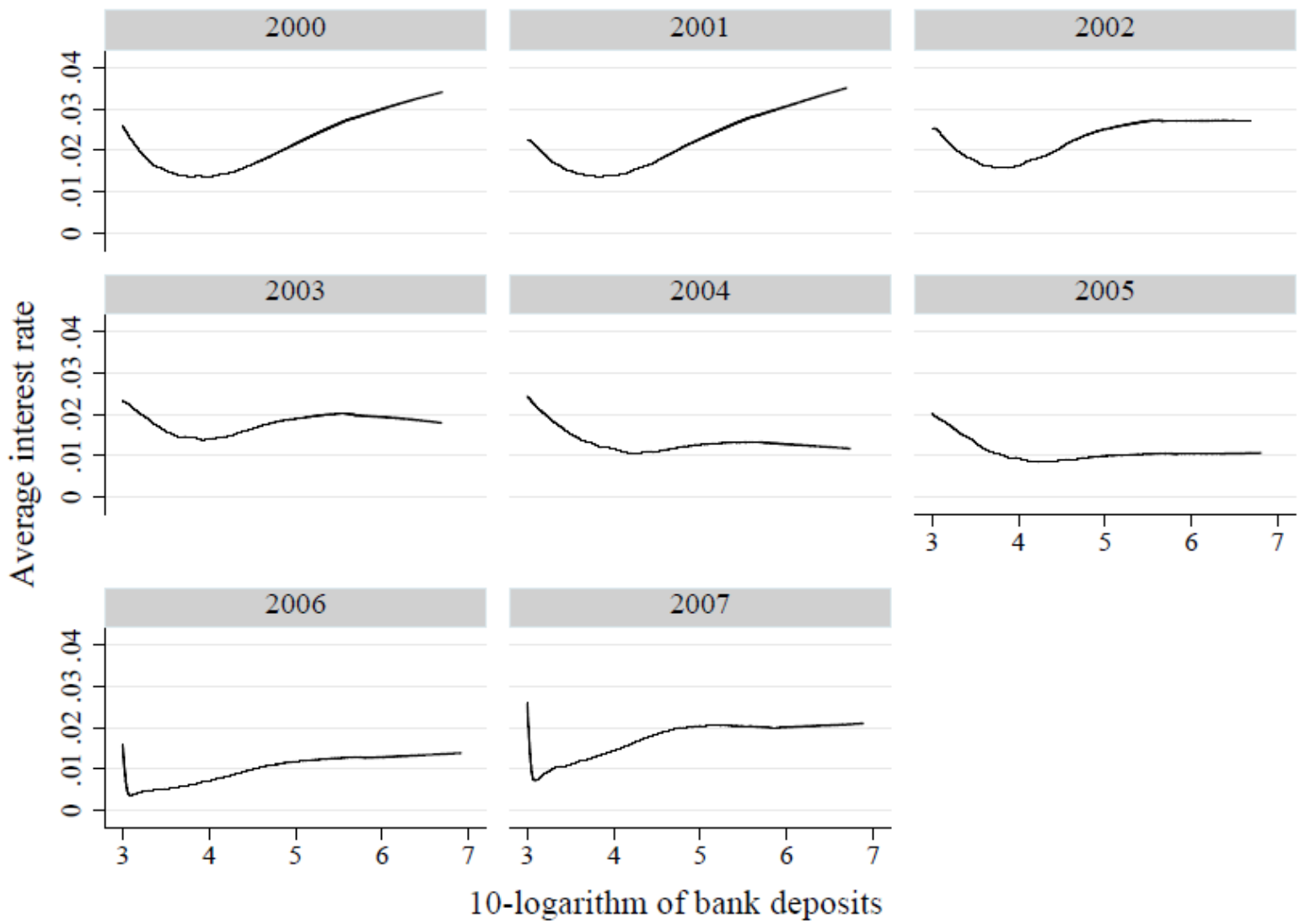
Figure A1b: Asset yields across the distribution in 2000-2012: Corporate shares

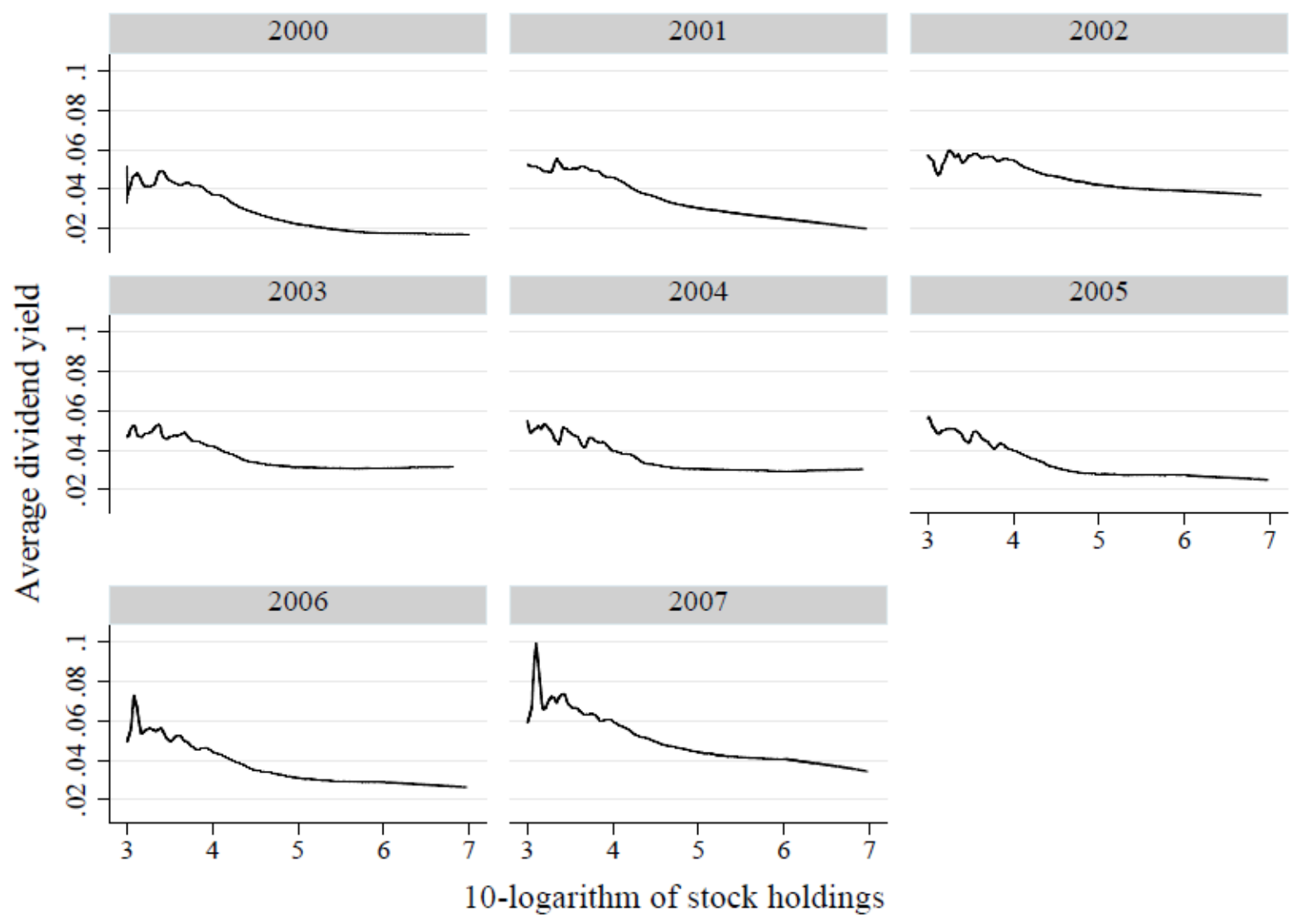


Figure A1c: Asset yields across the distribution in 2000-2012: Bank debt.

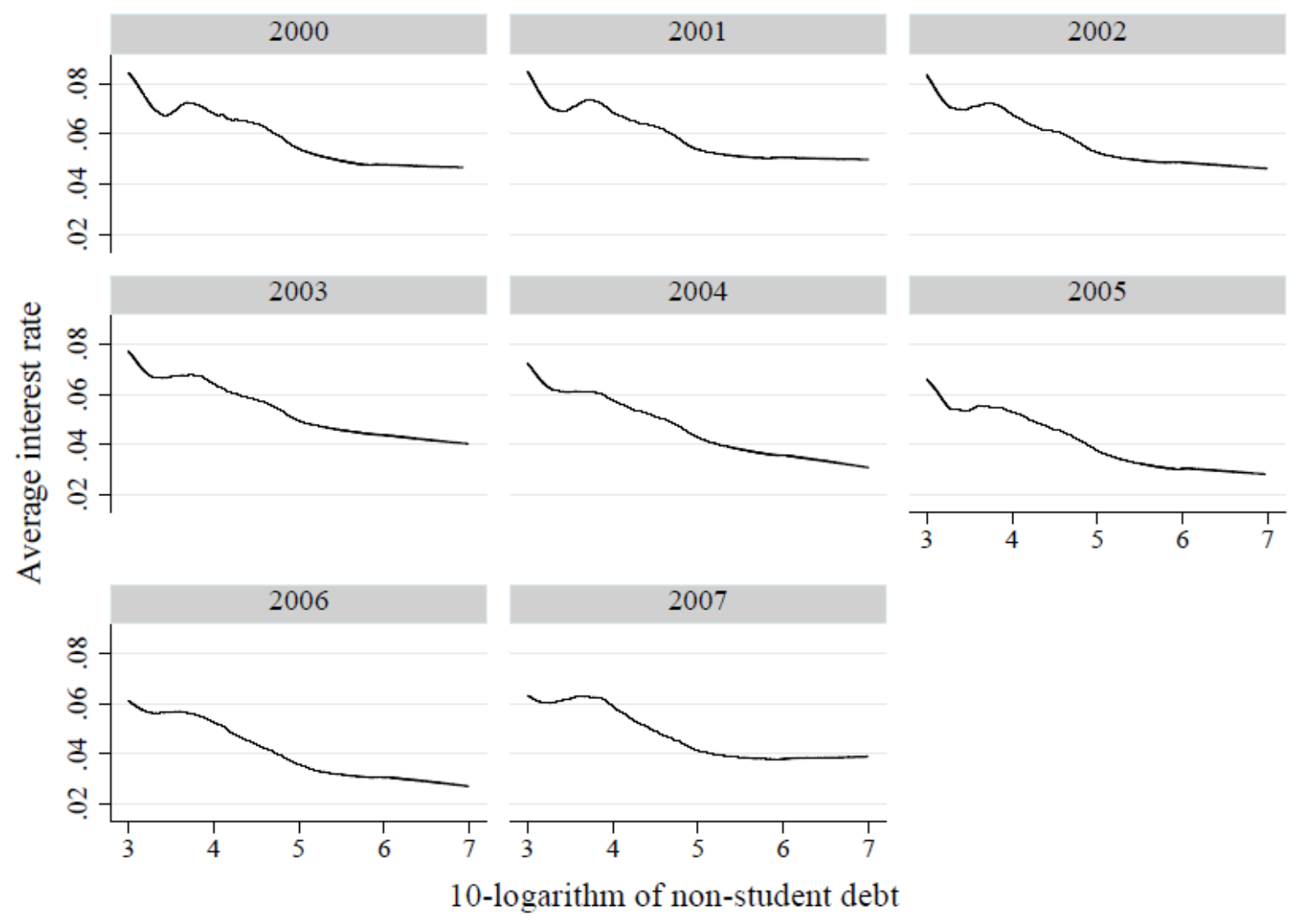


Figure A1d: Asset yields across the distribution in 2000-2012: Total return.
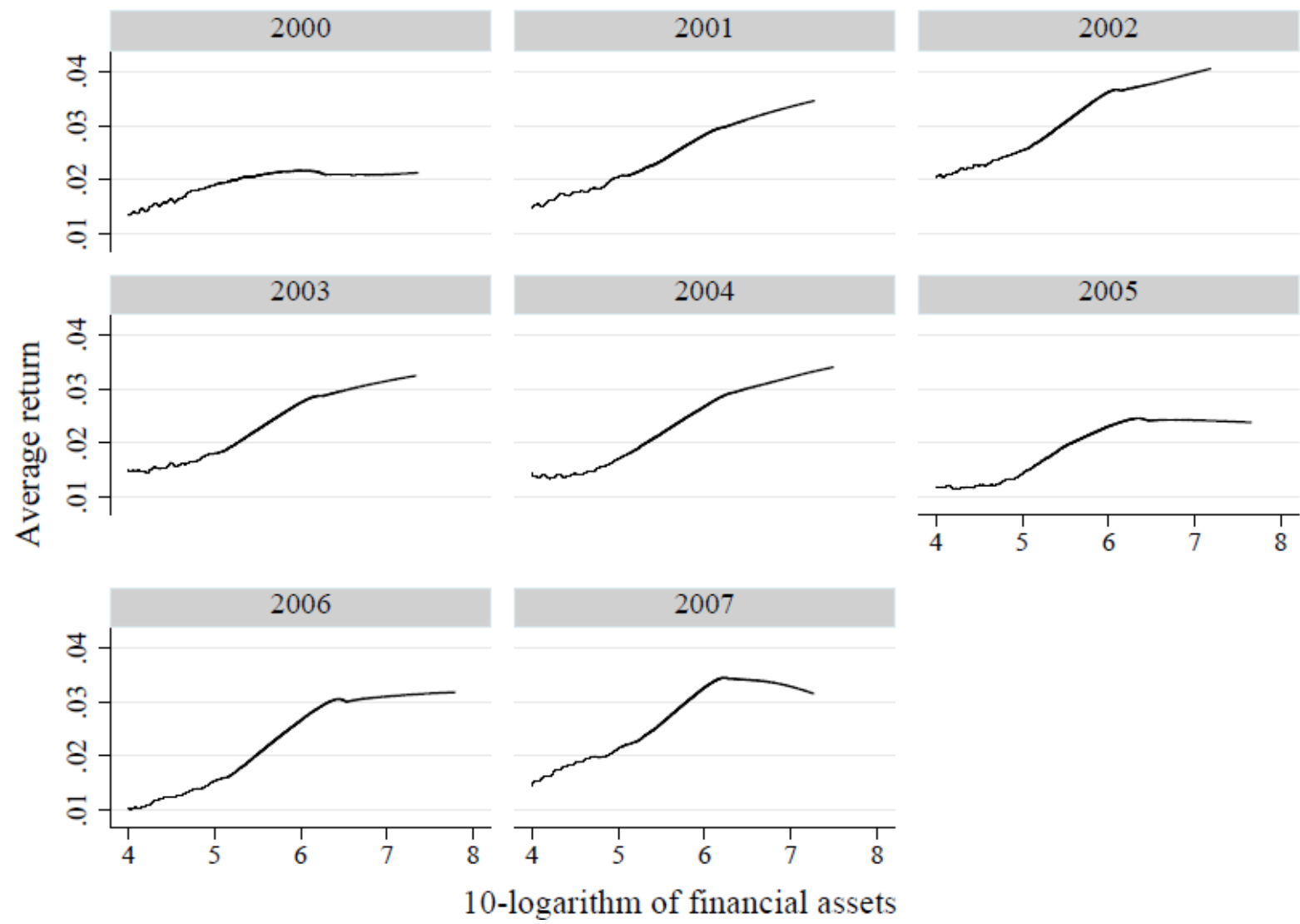
Figure A2: Goodness-of-fit of capitalized wealth by asset class in 2000, 2004, 2007.

a) Real estate

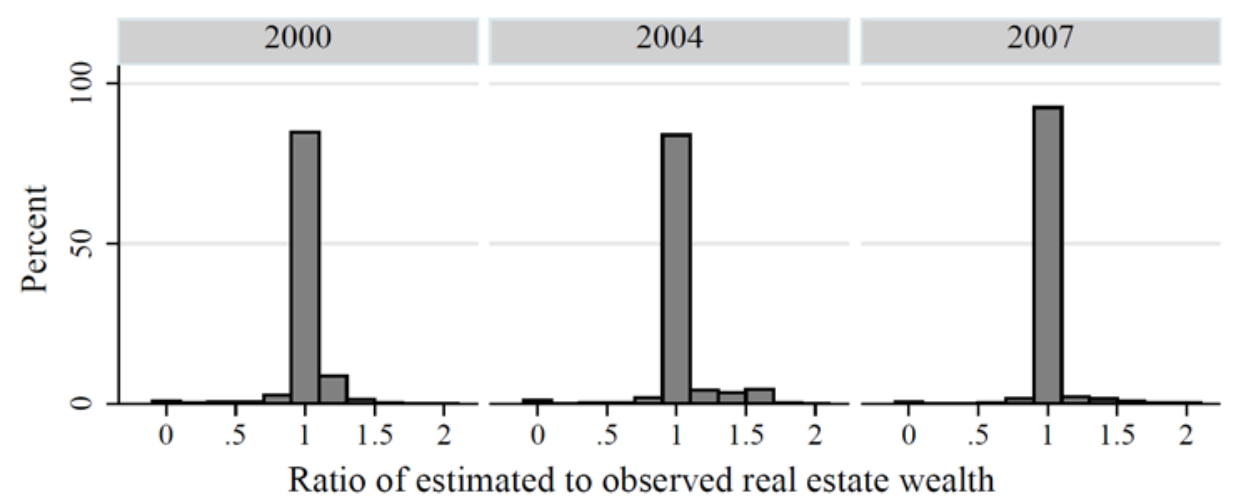

b) Bank deposits

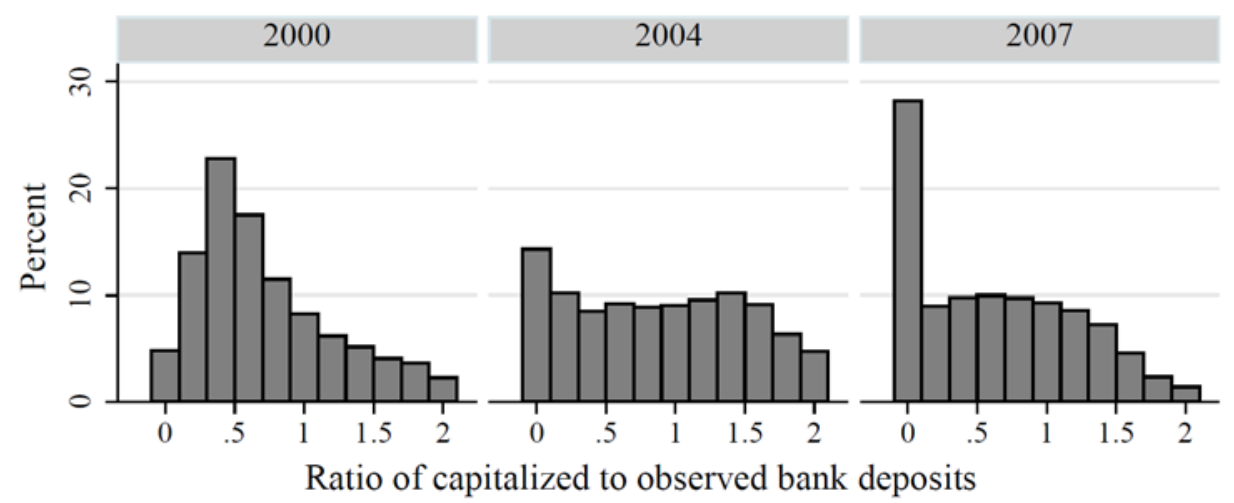

c) Corporate shares

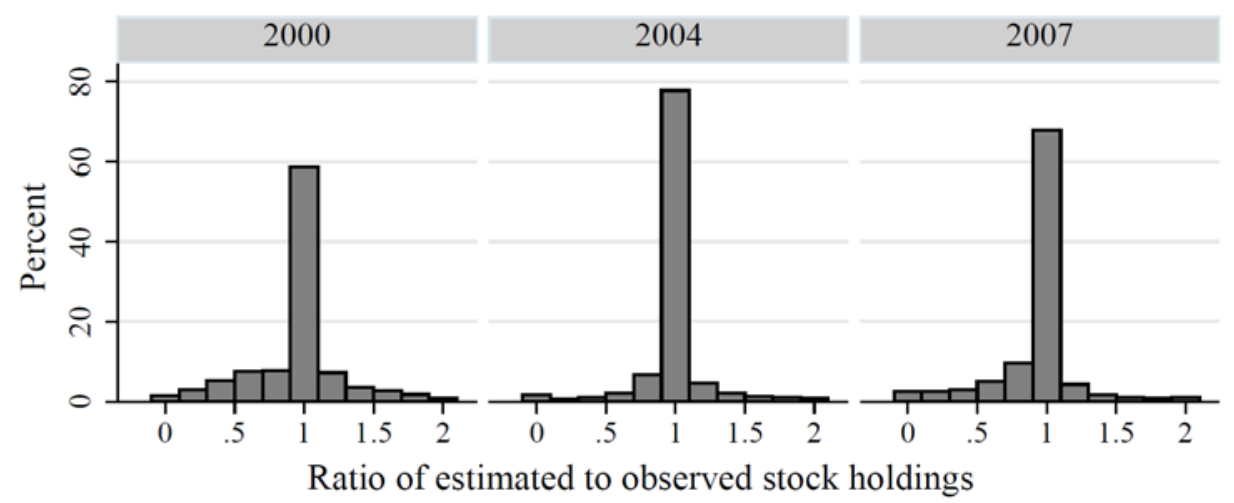


d) Gross assets

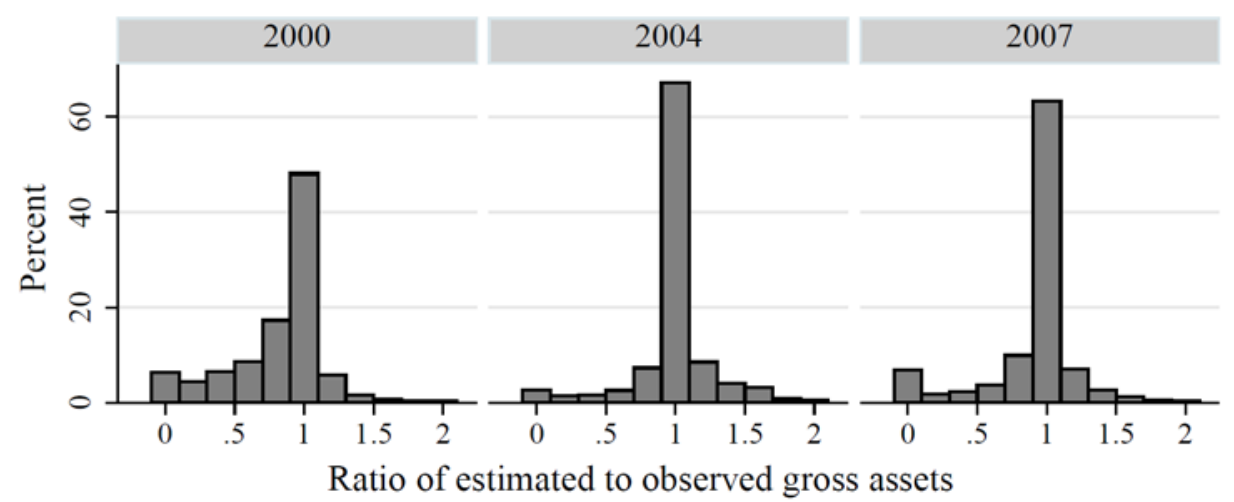

e) Bank debt

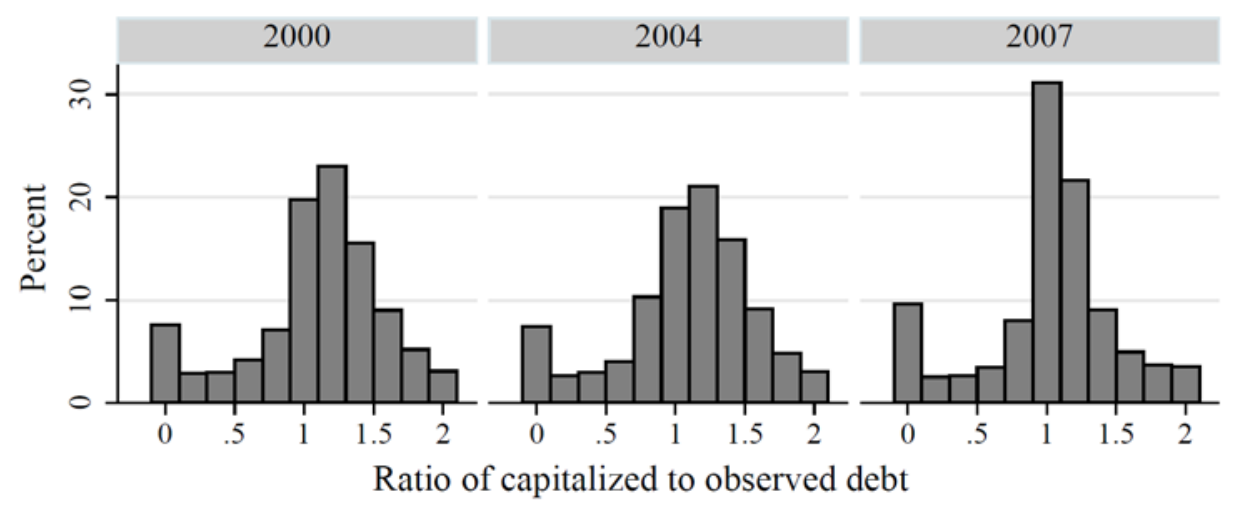

f) Net wealth

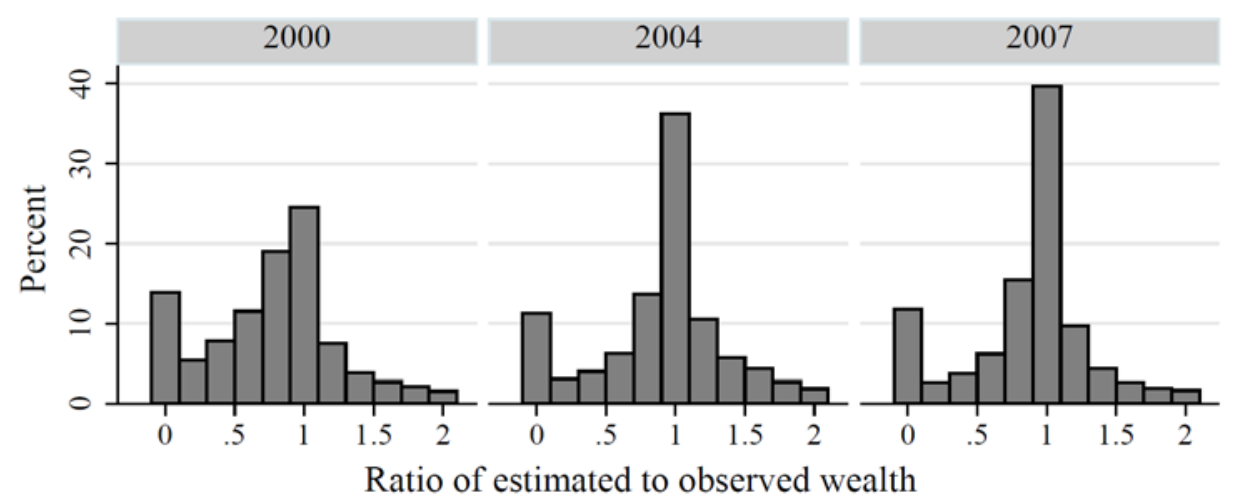


Figure A3: Average wealth in deciles: New estimates vs Wealth Register, full.

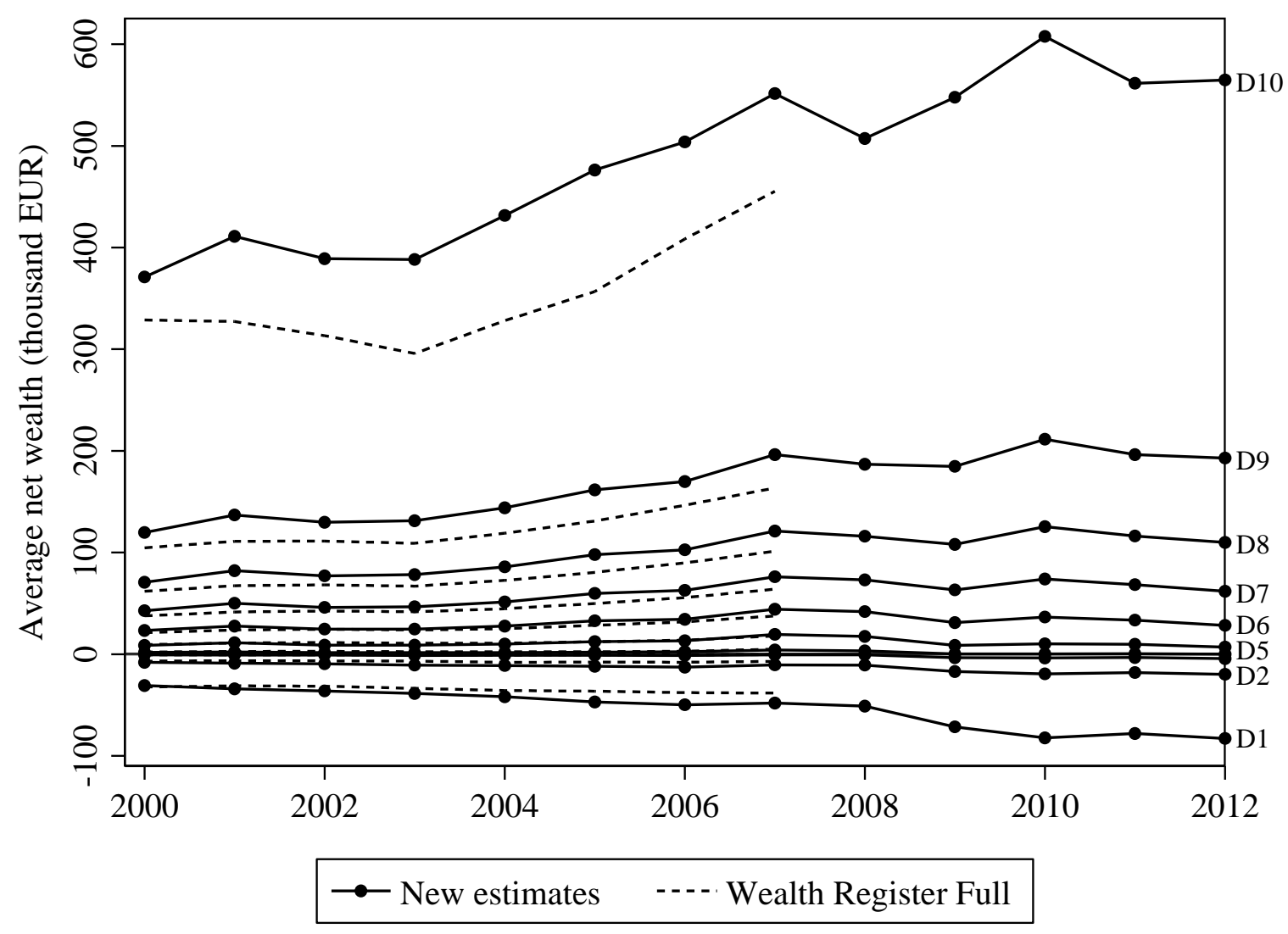

Note: See Figure A4. 
Figure A4: Gini comparison: New estimates vs Wealth Register (two versions)

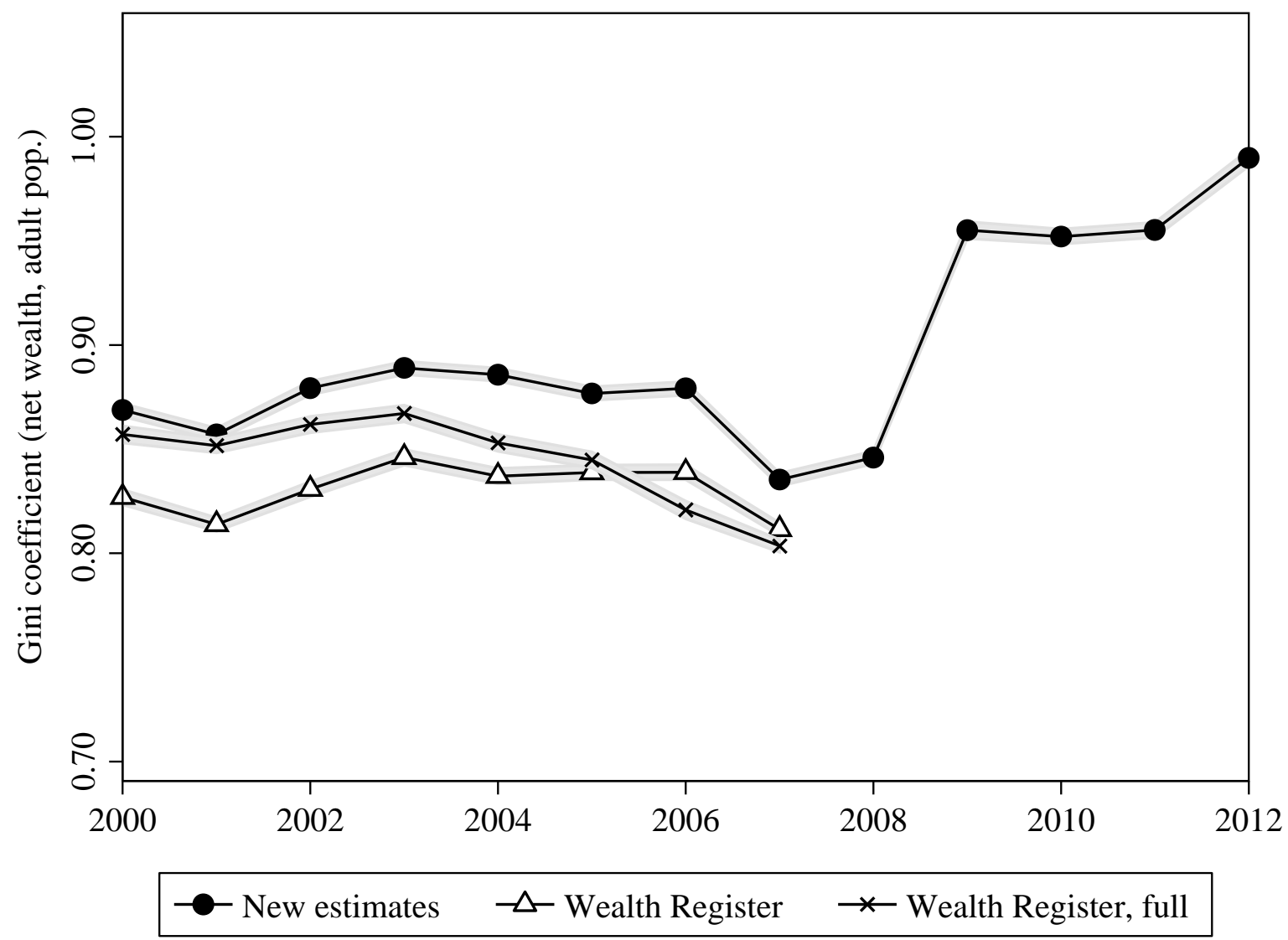

Note: The difference between "Wealth Register" and "Wealth Register, full" is a few asset classes (bonds, stock options and some minor financial assets) that are not covered by our new estimates and therefore also excluded in the main reference series, "Wealth Register". 
Figure A5: Top wealth shares: New estimates vs Wealth Register

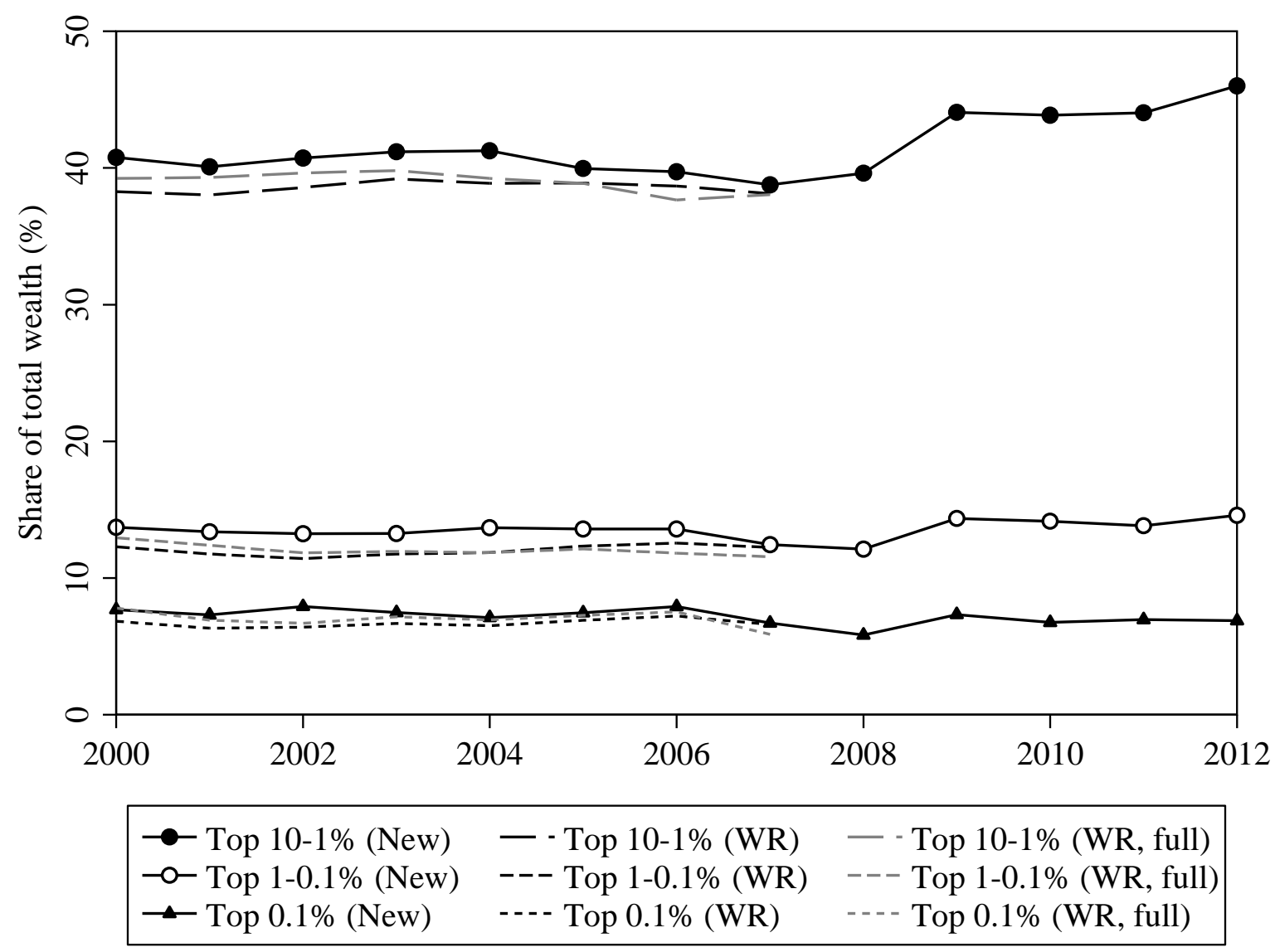

Note: See Figure A4. 
Figure A6: Kernel densities: New estimates vs Wealth Register

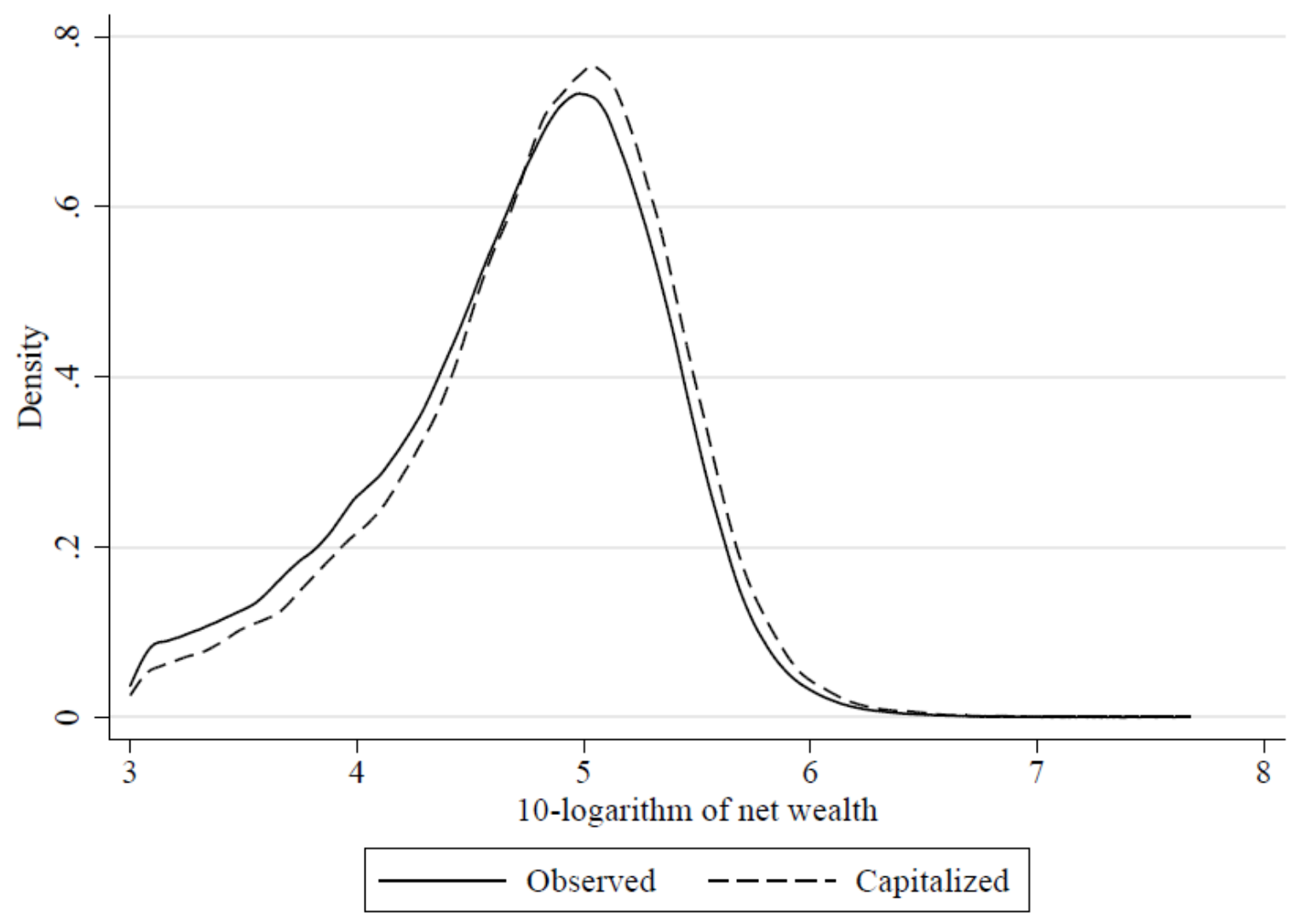


Table A1: Gini coefficients and top wealth shares in Sweden (net wealth, adult population).

\begin{tabular}{|c|c|c|c|c|c|c|c|c|}
\hline & \multicolumn{4}{|c|}{ New estimates } & \multicolumn{4}{|c|}{ Wealth Register } \\
\hline & Тор10\% & Тор1\% & Top0.1\% & Gini & Top10\% & Тор1\% & Top0.1\% & Gini \\
\hline 2000 & 62.18 & 21.41 & 7.69 & 0.869 & 59.98 & 20.75 & 7.81 & 0.857 \\
\hline 2001 & 60.78 & 20.69 & 7.30 & 0.857 & 58.62 & 19.32 & 6.92 & 0.852 \\
\hline 2002 & 61.87 & 21.16 & 7.92 & 0.879 & 58.17 & 18.53 & 6.69 & 0.862 \\
\hline 2003 & 61.93 & 20.75 & 7.48 & 0.889 & 58.93 & 19.12 & 7.17 & 0.867 \\
\hline 2004 & 62.05 & 20.79 & 7.11 & 0.886 & 58.04 & 18.81 & 6.94 & 0.853 \\
\hline 2005 & 61.00 & 21.05 & 7.46 & 0.877 & 58.28 & 19.41 & 7.27 & 0.845 \\
\hline 2006 & 61.23 & 21.50 & 7.91 & 0.879 & 57.01 & 19.35 & 7.53 & 0.821 \\
\hline 2007 & 57.93 & 19.16 & 6.71 & 0.835 & 55.49 & 17.43 & 5.88 & 0.804 \\
\hline 2008 & 57.54 & 17.93 & 5.83 & 0.846 & & & & \\
\hline 2009 & 65.76 & 21.69 & 7.33 & 0.943 & & & & \\
\hline 2010 & 64.76 & 20.90 & 6.75 & 0.939 & & & & \\
\hline 2011 & 64.81 & 20.79 & 6.96 & 0.942 & & & & \\
\hline 2012 & 67.48 & 21.48 & 6.88 & 0.976 & & & & \\
\hline
\end{tabular}

Note: Capitalized net wealth is our preferred measured used above, and register wealth is the net wealth in the Statistics Sweden's Wealth Register. 
Table A2: Simulated wealth shares under assumed allocations of unlisted business equity and defined benefit pension wealth.

\begin{tabular}{lllllll}
\hline $\begin{array}{l}\text { Unlisted corpo- } \\
\text { rate shares }\end{array}$ & $\begin{array}{l}\text { DB pension } \\
\text { wealth }\end{array}$ & Population & Bottom $90 \%$ & Top 10\% & Top 1\% & Top 0.1\% \\
\hline Amounts (BSEK): & & & & & & \\
None & None & 5,245 & 1,991 & 3,254 & 1,041 & 368 \\
& Semi-equal & 6,837 & 3,265 & 3,572 & 1,121 & 376 \\
\multirow{5}{*}{ Semi-equal } & Unequal & 6,837 & 2,787 & 4,050 & 1,280 & 447 \\
& None & 6,254 & 2,496 & 3,758 & 1,243 & 468 \\
\multirow{3}{*}{ Unequal } & Semi-equal & 7,846 & 3,769 & 4,077 & 1,323 & 476 \\
& Unequal & 7,846 & 3,292 & 4,554 & 1,482 & 548 \\
\multirow{5}{*}{ Shares (\%): } & None & 6,254 & 1,991 & 4,263 & 1,717 & 701 \\
None & Semi-equal & 7,846 & 3,265 & 4,581 & 1,797 & 709 \\
& Unequal & 7,846 & 2,787 & 5,059 & 1,956 & 780 \\
\multirow{5}{*}{ Semi-equal } & None & 100.00 & 37.96 & 62.04 & 19.85 & 7.01 \\
& Semi-equal & 100.00 & 47.75 & 52.25 & 16.39 & 5.49 \\
& Unequal & 100.00 & 40.77 & 59.23 & 18.72 & 6.54 \\
\multirow{2}{*}{ Unequal } & None & 100.00 & 39.91 & 60.09 & 19.88 & 7.49 \\
& Semi-equal & 100.00 & 48.04 & 51.96 & 16.86 & 6.07 \\
& Unequal & 100.00 & 41.95 & 58.05 & 18.89 & 6.99 \\
& None & 100.00 & 31.84 & 68.16 & 27.46 & 11.20 \\
\hline \hline & Semi-equal & 100.00 & 41.61 & 58.39 & 22.90 & 9.03 \\
& Unequal & 100.00 & 35.52 & 64.48 & 24.93 & 9.94 \\
\hline
\end{tabular}

Note: The allocations of the national total value of unlisted corporate shares are as follows: for "Semi-equal", half to the Bottom $90 \%$, half to the Top 10\%, 20 percent to the Top $1 \%$ and ten percent to the Top $0.1 \%$, and for "Unequal" everything to the Top $10 \%$, half to the Top $1 \%$ and 30 percent to the Top $0.1 \%$. The allocations of the national total value of defined benefit pension wealth are as follows: for "Semi-equal", 80 percent to the Bottom 90\%, 20 percent to the Top 10\%, 5 percent to the Top $1 \%$ and 0.5 percent to the Top $0.1 \%$, and for "Unequal" half to the Bottom $90 \%$, half to the Top $10 \%$, 15 percent to the Top $1 \%$ and 5 percent to the Top $0.1 \%$. 
Table A3: Decomposition of wealth inequality in Sweden.

\begin{tabular}{|c|c|c|c|c|c|}
\hline $\begin{array}{l}\text { Wealth compo- } \\
\text { nent }\end{array}$ & $\begin{array}{c}\text { Share of } \\
\text { wealth } \\
\left(S_{k}\right)\end{array}$ & $\begin{array}{l}\text { Gini } \\
\left(G_{k}\right)\end{array}$ & $\begin{array}{c}\text { Gini correla- } \\
\text { tion } \\
\left(R_{k}\right)\end{array}$ & $\begin{array}{l}\text { Absolute con- } \\
\text { tribution } \\
\left(I_{k}\right)\end{array}$ & $\begin{array}{l}\text { Relative con- } \\
\text { tribution } \\
\left(I_{k} / G\right)\end{array}$ \\
\hline \multicolumn{6}{|l|}{ Real estate } \\
\hline 2000 & 0.831 & 0.748 & 0.816 & 0.507 & $67.8 \%$ \\
\hline 2001 & 0.881 & 0.756 & 0.838 & 0.558 & $73.8 \%$ \\
\hline 2002 & 0.957 & 0.759 & 0.841 & 0.611 & $80.5 \%$ \\
\hline 2003 & 0.893 & 0.757 & 0.795 & 0.538 & $71.0 \%$ \\
\hline 2004 & 0.879 & 0.759 & 0.796 & 0.531 & $70.0 \%$ \\
\hline 2005 & 0.830 & 0.748 & 0.773 & 0.480 & $64.2 \%$ \\
\hline 2006 & 0.791 & 0.748 & 0.746 & 0.441 & $59.0 \%$ \\
\hline 2007 & 0.839 & 0.750 & 0.801 & 0.504 & $67.2 \%$ \\
\hline 2008 & 0.914 & 0.751 & 0.811 & 0.557 & $74.1 \%$ \\
\hline 2009 & 0.842 & 0.753 & 0.728 & 0.461 & $61.3 \%$ \\
\hline 2010 & 0.832 & 0.760 & 0.763 & 0.483 & $63.5 \%$ \\
\hline 2011 & 0.877 & 0.768 & 0.779 & 0.525 & $68.4 \%$ \\
\hline 2012 & 0.830 & 0.772 & 0.746 & 0.478 & $61.9 \%$ \\
\hline \multicolumn{6}{|l|}{ Apartments } \\
\hline 2000 & 0.104 & 0.943 & 0.570 & 0.056 & $5.9 \%$ \\
\hline 2001 & 0.097 & 0.939 & 0.486 & 0.044 & $4.7 \%$ \\
\hline 2002 & 0.119 & 0.944 & 0.562 & 0.063 & $6.7 \%$ \\
\hline 2003 & 0.159 & 0.936 & 0.619 & 0.092 & $9.8 \%$ \\
\hline 2004 & 0.164 & 0.921 & 0.573 & 0.087 & $9.4 \%$ \\
\hline 2005 & 0.185 & 0.919 & 0.625 & 0.106 & $11.6 \%$ \\
\hline 2006 & 0.197 & 0.917 & 0.636 & 0.115 & $12.5 \%$ \\
\hline 2007 & 0.184 & 0.915 & 0.583 & 0.098 & $10.7 \%$ \\
\hline 2008 & 0.196 & 0.915 & 0.572 & 0.103 & $11.2 \%$ \\
\hline 2009 & 0.242 & 0.917 & 0.681 & 0.151 & $16.5 \%$ \\
\hline 2010 & 0.234 & 0.919 & 0.704 & 0.151 & $16.4 \%$ \\
\hline 2011 & 0.241 & 0.922 & 0.719 & 0.160 & $17.3 \%$ \\
\hline 2012 & 0.267 & 0.924 & 0.760 & 0.188 & $20.3 \%$ \\
\hline \multicolumn{6}{|l|}{ Bank deposits } \\
\hline 2000 & 0.124 & 0.880 & 0.803 & 0.088 & $10.0 \%$ \\
\hline 2001 & 0.127 & 0.860 & 0.786 & 0.086 & $10.0 \%$ \\
\hline 2002 & 0.144 & 0.867 & 0.790 & 0.098 & $11.3 \%$ \\
\hline 2003 & 0.149 & 0.865 & 0.793 & 0.103 & $11.9 \%$ \\
\hline 2004 & 0.138 & 0.899 & 0.810 & 0.100 & $11.1 \%$ \\
\hline 2005 & 0.134 & 0.914 & 0.824 & 0.101 & $11.1 \%$ \\
\hline 2006 & 0.141 & 0.874 & 0.795 & 0.098 & $11.2 \%$ \\
\hline 2007 & 0.146 & 0.844 & 0.779 & 0.096 & $11.3 \%$ \\
\hline 2008 & 0.166 & 0.829 & 0.778 & 0.107 & $12.9 \%$ \\
\hline 2009 & 0.178 & 0.906 & 0.849 & 0.137 & $15.1 \%$ \\
\hline 2010 & 0.167 & 0.888 & 0.818 & 0.121 & $13.7 \%$ \\
\hline 2011 & 0.190 & 0.838 & 0.794 & 0.126 & $15.1 \%$ \\
\hline 2012 & 0.208 & 0.855 & 0.817 & 0.145 & $17.0 \%$ \\
\hline
\end{tabular}


Table A3 (cont'd): Decomposition of wealth inequality in Sweden.

\begin{tabular}{|c|c|c|c|c|c|}
\hline $\begin{array}{l}\text { Wealth compo- } \\
\text { nent }\end{array}$ & $\begin{array}{c}\text { Share of } \\
\text { wealth } \\
\left(S_{k}\right)\end{array}$ & $\begin{array}{l}\text { Gini } \\
\left(G_{k}\right)\end{array}$ & $\begin{array}{c}\text { Gini correla- } \\
\text { tion } \\
\left(R_{k}\right)\end{array}$ & $\begin{array}{l}\text { Absolute con- } \\
\text { tribution } \\
\left(I_{k}\right)\end{array}$ & $\begin{array}{l}\text { Relative con- } \\
\text { tribution } \\
\left(I_{k} / G\right)\end{array}$ \\
\hline \multicolumn{6}{|l|}{ Corporate shares } \\
\hline 2000 & 0.158 & 0.949 & 0.886 & 0.133 & $14.0 \%$ \\
\hline 2001 & 0.133 & 0.949 & 0.882 & 0.112 & $11.8 \%$ \\
\hline 2002 & 0.095 & 0.949 & 0.861 & 0.078 & $8.2 \%$ \\
\hline 2003 & 0.119 & 0.947 & 0.870 & 0.098 & $10.4 \%$ \\
\hline 2004 & 0.129 & 0.948 & 0.876 & 0.107 & $11.3 \%$ \\
\hline 2005 & 0.144 & 0.951 & 0.889 & 0.122 & $12.8 \%$ \\
\hline 2006 & 0.157 & 0.953 & 0.902 & 0.135 & $14.1 \%$ \\
\hline 2007 & 0.115 & 0.955 & 0.890 & 0.097 & $10.2 \%$ \\
\hline 2008 & 0.073 & 0.954 & 0.844 & 0.059 & $6.2 \%$ \\
\hline 2009 & 0.108 & 0.964 & 0.887 & 0.093 & $9.6 \%$ \\
\hline 2010 & 0.111 & 0.960 & 0.883 & 0.094 & $9.8 \%$ \\
\hline 2011 & 0.084 & 0.960 & 0.863 & 0.070 & $7.2 \%$ \\
\hline 2012 & 0.093 & 0.960 & 0.870 & 0.078 & $8.1 \%$ \\
\hline \multicolumn{6}{|l|}{ Mutual funds } \\
\hline 2000 & 0.142 & 0.926 & 0.811 & 0.107 & $11.6 \%$ \\
\hline 2001 & 0.127 & 0.871 & 0.753 & 0.083 & $9.6 \%$ \\
\hline 2002 & 0.094 & 0.863 & 0.715 & 0.058 & $6.7 \%$ \\
\hline 2003 & 0.113 & 0.856 & 0.736 & 0.071 & $8.3 \%$ \\
\hline 2004 & 0.112 & 0.855 & 0.741 & 0.071 & $8.3 \%$ \\
\hline 2005 & 0.121 & 0.848 & 0.745 & 0.076 & $9.0 \%$ \\
\hline 2006 & 0.143 & 0.867 & 0.791 & 0.098 & $11.3 \%$ \\
\hline 2007 & 0.112 & 0.859 & 0.754 & 0.073 & $8.5 \%$ \\
\hline 2008 & 0.084 & 0.866 & 0.720 & 0.052 & $6.0 \%$ \\
\hline 2009 & 0.109 & 0.868 & 0.756 & 0.072 & $8.3 \%$ \\
\hline 2010 & 0.104 & 0.861 & 0.738 & 0.066 & $7.7 \%$ \\
\hline 2011 & 0.094 & 0.862 & 0.730 & 0.059 & $6.9 \%$ \\
\hline 2012 & 0.110 & 0.865 & 0.748 & 0.071 & $8.3 \%$ \\
\hline \multicolumn{6}{|l|}{ Debt } \\
\hline 2000 & -0.360 & -0.684 & -0.089 & -0.022 & $3.2 \%$ \\
\hline 2001 & -0.365 & -0.682 & -0.104 & -0.026 & $3.8 \%$ \\
\hline 2002 & -0.409 & -0.685 & -0.104 & -0.029 & $4.3 \%$ \\
\hline 2003 & -0.434 & -0.676 & -0.044 & -0.013 & $1.9 \%$ \\
\hline 2004 & -0.423 & -0.676 & -0.039 & -0.011 & $1.6 \%$ \\
\hline 2005 & -0.415 & -0.676 & -0.033 & -0.009 & $1.4 \%$ \\
\hline 2006 & -0.429 & -0.673 & -0.026 & -0.007 & $1.1 \%$ \\
\hline 2007 & -0.395 & -0.678 & -0.122 & -0.033 & $4.8 \%$ \\
\hline 2008 & -0.433 & -0.685 & -0.106 & -0.032 & $4.6 \%$ \\
\hline 2009 & -0.480 & -0.685 & 0.087 & 0.029 & $-4.2 \%$ \\
\hline 2010 & -0.448 & -0.682 & 0.077 & 0.024 & $-3.4 \%$ \\
\hline 2011 & -0.486 & -0.684 & 0.004 & 0.001 & $-0.2 \%$ \\
\hline 2012 & -0.509 & -0.686 & 0.047 & 0.016 & $-2.4 \%$ \\
\hline
\end{tabular}

Note: Net wealth Gini decomposition (Lerman and Yithzaki,1985). $S_{k}$ is component $k$ 's share in net wealth, $G_{k}$ its Gini and $R_{k}$ its correlation with net wealth; $I_{k}=S_{k} G_{k} R_{k}$ its contribution to the net wealth Gini. 